\title{
LAMELAS (BANDAS ONDULADAS) EMARGISSOLO VERMELHO- AMARELO COMO INDICADORES DA EVOLUÇÃO DO RELEVO: O CASO DAS COLINAS MÉDIAS DO PLATÔ DE BAURU (SP) ${ }^{1}$
}

\author{
Leonardo José Cordeiro Santos \\ Departamento de Geografia - Universidade Federal do Paraná,Tel. (41) 3361-3479 \\ e-mail: santos@ufpr.br \\ Selma Simões de Castro \\ Instituto de Estudos Sócio-Ambientais - Universidade Federal de Goiás ,Telfax: (62) 5211095 \\ e-mail:selma@iesa.ufg.br
}

\begin{abstract}
Resumo
No Platô de Bauru - um pequeno platô do oeste do estado de São Paulo - domina relevo rebaixado e dissecado em suas bordas, considerado residual de condições tropicais denudacionais pós-cretáceas. Compõe conjunto dominado por colinas amplas e médias suportadas por arenitos finos cretácicos da Bacia Sedimentar do Paraná. As colinas médias apresentam perfil convexo-côncavo-convexo, ao longo do qual se desenvolve sistema pedológico constituído de Latossolo Vermelho-Amarelo nos topos convexos, Argissolo Vermelho-Amarelo nas vertentes, progressivamente hidromorfizado para juzante, onde passa ao Gleissolo na base das vertentes. Nos segmentos médios de suas vertentes, onde se desenvolveu Argissolo Vermelho Amarelo, o horizonte E arenoso apresenta numerosas lamelas (ou bandas onduladas), na forma de pendúculos em semi-arco conectados ao horizonte B subjacente, argiluvial e hidromomorfizado (Btg), ou ainda de faixas estreitas desconectadas. Ambas concentram constituintes finos (areia fina, argila e oxidohidróxido de ferro). A origem dessas lamelas é controversa e não se conhece suas relações com a evolução do próprio relevo. Neste artigo, inicialmente apresenta-se breve revisão sobre as diversas interpretações a respeito da origem e dos mecanismos de formação e evolução dessas lamelas. Com o intuito de embasar a discussão, o estudo de um perfil representativo desse solo é apresentado através de descrições morfológicas e micromorfológicas acompanhadas de ensaios físico-hídricos (granulometria, porosidade e condutividade hidráulica saturada) de amostras coletadas em campo. Os resultados revelam que as lamelas estudadas são de origem pedogenética relacionada a processo de hidromorfia suspensa e e-iluviação, as quais teriam facilitado também a instalação de fluxos hídricos superficiais e subsuperficiais verticais e laterais concentrados nesse segmento, favorecendo sua instabilidade e dissecação posterior por erosão hídrica. Discute-se as causas desse fenômeno e levanta-se a possibilidade de rebaixamento local recente do nível dos talvegues como indutor de reajustes hidráulicos das vertentes pré-existentes, sendo as lamelas testemunhas dos reajustes pedológicos relacionados e ainda funcionais.
\end{abstract}

Palavras chave: Relação Pedogênese x Morfogênese, Platô de Bauru, colinas médias, Argissolo Vermelho-Amarelo, lamelas (bandas onduladas), hidromorfia suspensa, e-iluviação.

\begin{abstract}
The big structural geomorphic surface situated in the west of the State of São Paulo, Brazil, and named Paulista OccidentalPlateau is supported by fine sandstones dated from Cretaceous of Paraná Sedimentary Basin and developed under Post-Cretaceous tropical denudation environments, compound residual and dissected plateaux. One of them, representing one of the mostly lowered and dissected surface, named Bauru Plateau, situated on its center-southern sector is constituted by big smoothed
\end{abstract}

${ }_{1}^{1}$ Parte da Dissertação de Mestrado do primeiro autor, apresentada ao Departamento de Geografia da USP em abril de 1995, não publicada, em versão atualizada. 
interfluves with length slopes related to the typical Red Ferralsol (Oxisol in USA and Latosol in Brazil) in center part and medium dissected interfluves to the boarders, with convex-concave-convex slopes related to soil succession interpreted as lateral pedological transformation system, constituted by Red and Red Yellow Ferralsol on the tops, Red Yellow Ferralsol with elevated textural gradient (Ultisol in USA and Argisol in Brazil) dominant in middle slopes, and Gleisol on the foothills and alluvial plain. This Red Yellow Ferralsol with eluvial horizon (E) frequently presenting numerous suspended and undulated fine yellowish sandy clayed lamellae, or red, thick, clayed and connected to the subjacent hydromorphic B argilic horizon (Btg) by a little peduncle projected in semi-arc to the foothill, is related to controversies about its origin. One representative soil profile from a typical toposequence was selected in order to illustrate the lamellae genesis and its relationships with the hydromorphic B horizon and the hillslope evolution. Macromophological and micromorphological study and physical hydrological measures (texture, porosity and saturated hydraulic conductivity) over collected soil samples on length pit, was done. The results emphasizes the formation of lamellae and Btg horizon by e-illuvial mechanisms related to the hydromorphic action in the E-Btg transition and elluviation in E horizons associated to a suspended water level; a transitory soil features in pedological development of medium slope by consequence of internal lateral loss of clay and residual accumulation of sandy in superficial horizon conducting to a topographic deepening and potentialized by superficial concentrated water flows in favors to dissection. The origin of these processes is attributed to successive hydraulic adjustments of the interfluves inducted by depression of the base level under humid post-cretaceous climate. The lamella features representing the notables preserved features of the soil geomorphology development witch is functional until present.

Keywords: Pedogenesis and Morphogenesis, Plateaux of Bauru, medium dissected interfluves, Red Yellow Ferralsol, lamellae, suspended water level, e-illuvial processes.

\section{Introdução}

As lamelas foram identificadas e estudadas no início do século XX (Wilcox, 1906 apud Rawling, 2000), mas vêm sendo melhor investigadas a partir da década de 1950 e conhecidas com essa denominação desde a década de 1960, como proposta pelo Soil Survey Staff (1960). É generalizada, desde então, a concepção de que correspondem a faixas de concentração de frações finas, basicamente argilas, siltes, óxido-hidróxidos de ferro e/ou humatos, em geral de espessura centimétrica. De conformação ondulada, normalmente situadas nos horizontes superiores arenosos dos solos, com os quais contrastam em geral fortemente, ou em sedimentos arenosos (depósitos), em geral Quaternários (Rawling, 2000), onde foram melhor estudadas inicialmente, são frequentemente relacionadas a processos deposicionais Quartenários.

Os estudiosos adotaram essa denominação de lamelas, seja em função de sua constituição, atribuindo-lhes nomes em função de sua constituição, como bandas texturais, lamelas texturais, bandas argilosas, bandas argiloferruginosas; de sua cor, como multibandas vermelhoamarelas; ou em função dos processos e mecanismos de sua formação, como estruturas de dissipação, estruturas de infiltração, estruturas iluviais, sedimentares, ilúviosedimentares e similares, como sintetizam Rawling (2000) e Paisani (2004a) em suas revisões sobre o tema, os quais também destacam o discenso sobre sua gênese, (embora a iluvial e a sedimentar predominem na literatura).

Quanto ao tempo necessário para sua formação e evolução, igualmente não há consenso. Embora predomine a interpretação que as associam aos ambientes e sedimentos Quaternários pretéritos, estudos em situação e tempo experimental produziram bandas simultâneas em diferentes profundidades, fazendo supor que podem ter desenvolvimento atual e extremamente rápido (Bond, 1986).

Após longo período em que estudos de caso dominaram a literatura, Rawling (2000), ao apresentar uma revisão bastante completa, interessante e atualizada sobre o assunto, ressalta que sua origem ainda permanece controversa, dificultando uma classificação geral e completa. No entanto, ainda que concorde com Ritter (1995), no sentido de que as lamelas podem ajudar a reconstituir a história geomorfológica de uma área, ele pondera que a terminologia variada e suas diferentes interpretações quanto à sua origem podem confundir os geomorfólogos, pois que ora valorizam os ambientes de formação, ora os mecanismos de formação ou a sua evolução em si mesma. Mesmo assim foram propostas duas classificações para sua origem, nos finais das décadas de 1950 e 1960, por Wurman et al (1959) e Djikermann et al (1967), as quais podem ser consideradas mais abrangentes, além de pioneiras.

Wurman et al (1959), por exemplo, as classificaram quanto à origem em petrogenéticas (herdadas de substrato geológico sedimentar), pedogenéticas (produtos de processos pedogenéticos de iluviação) e pedopetrogenéticas (consideradas mistas). Já Djikermann et al (1967) as classificaram quanto aos mecanismos de formação em sedimentares, ilúvio-sedimentares e iluviais. Na primeira os autores se basearam em sua concordância ou não com a superfície atual do terreno, bem como em dados de sua constituição e arranjo interno, afirmando que as 
petrogenéticas são paralelas entre si, contêm argila fracamente orientada e silte constituindo estruturas sedimentares; e as pedogenéticas são paralelas ao terreno, configuram estruturas sedimentares cruzadas e cortadas (cross-cut), ou ocorrem em materiais de origem não estratificados, contendo argilas na forma de revestimentos e pontes entre grãos primários; e finalmente as pedopetrogenéticas que são paralelas entre si e constituídas também por argilas na forma de revestimentos e pontes como nas anteriores. Já na segunda classificação (Djikermann et al,1967), os autores basearam-se em critérios essencialmente estratigráficos, critérios esses muito parecidos para o desenvolvimento dos argumentos que foram adotados no Brasil e logo depois, como a seguir.

No Brasil o termo mais consagrado para tais feições é o de bandas onduladas, desde os trabalhos considerados pioneiros (Comissão de Solos, 1960; Queiroz Neto, 1975; Suguio \& Coimbra, 1976), denominação essa preferida até hoje. As interpretações sobre sua origem também variaram ao longo do tempo. Bigarella (1974) as interpretara como estruturas de dissipação (retrabalhamento de dunas), Suguio \& Coimbra (1976), como estruturas sedimentares herdadas dos arenitos cretáceos do Grupo Bauru, realçadas pela pedogênese e Queiroz Neto (1975), que as interpretara como produto de coluvionamentos argilosos. Portanto, seriam todas de origem sedimentar.

Na década de 1980 em diante, sobretudo na década de 1990, quando passaram a ser mais estudadas, particularmente por pedólogos e em perfis de Argissolos (ex-Podzólicos Vermelho-Amarelos) e de Neossolos Quartzarênicos (exAreias Quartzosas) (Embrapa, 1999), solos em que mais foram estudadas, é quando surge pela primeira vez a interpretação de que seriam feições residuais da transformação de horizontes $\mathrm{Bt}$ em $\mathrm{E}$ de Argissolos, em conseqüência de mecanismos de e-iluviação associada a fenômeno de degradação atual por hidromorfia suspensa no horizonte B. É quando Queiroz Neto et al (1981) abandonaram todas as interpretações anteriores, como detalhadamente relatado por Castro (1989a).

É muito oportuno lembrar que antes da década de 1980, tanto no Brasil como no exterior, os estudos comumente não utilizavam micromorfologia, análises geoquímicas e cristaloquímicas detalhadas das bandas, dos horizontes ou subhorizontes interbandas e dos horizontes relacionados, tampouco as estudavam em continuum, isto é, ao longo de sua trajetória, ou seja, de seu aparecimento até o seu desaparecimento, no sentido lateral, incluindo os horizontes associados, na busca de evidências de filiações genéticoevolutivas entre elas, os horizontes e as formas das vertentes. Pela aplicação desse procedimento, merecem destaque Castro \& Curmi (1987) e Castro (1989a) por terem sido pioneiros no país na adoção desses princípios de observação, coleta e estudo microscópico e analítico das bandas onduladas.

Desde então algumas interpretações anteriores têm sido revistas e mesmo mudadas (Paisani, 2004b). Hoje já se sabe que podem ocorrer em vários tipos de solos, sejam pedogeneticamente desenvolvidos (Queiroz Neto et al, 1981; Castro, 1989 a; Fernandes Barros et al, 1991), ou não (Rolim \& Santos, 1994; Oliveira et al, 1998) e também em paleossolos (Paisani, 2004 b), além de novos estudos terem sido feitos.

Assim, na literatura atual, dominam duas tendências principais: a iluviação e a sedimentação. Essas duas tendências podem ser denominadas, simplificadamente de: a) geogenéticas (Paisani, 2001), como feições sedimentares singenéticas herdadas do material de origem, independentemente de sua idade ou da denominação adotada pelos autores e b) pedogenéticas, ou seja, de iluviação ou de $e$-iluviação.

Neste artigo, inicialmente se discute as interpretações controversas a respeito da origem e mecanismos de formação das bandas onduladas de maneira mais aprofundada, e, a seguir, apresenta-se as evidências das suas relações com a gênese e evolução do Argissolo Vermelho-Amarelo, bem como das vertentes relacionadas, com base nos resultados obtidos em estudos macromorfológicos, micromorfológicos e de medidas físico-hídricas de amostras de um perfil desse solo, representativo das colinas médias do Platô de Bauru, um pequeno ressalto topográfico bastante dissecado situado no Planalto Ocidental Pulista, com o objetivo de contribuir para a compreensão do fenômeno.

Valoriza-se também o método de levantamento detalhado de solos em toposseqüências, tal como entendidas por Boulet (1988, 1992), Queiroz Neto (1988), Ruellan (1988) e Castro (1989a), porém numa abordagem integrada da paisagem geomorfológica, hoje denominada de multi-escala, por partir do contexto da paisagem e prosseguir até o nível microscópico (micromorfologia), e multi-analítica, por ser acompanhada de análises físicas, geoquímicas e mineralógicas para identificação de constituintes e seus estados, e várias vezes de ensaios físico-hídricos em campo e laboratório para identificação dos padrões de circulação e fluxos hídricos associados (Salomão, 1994). Às vezes também aprofundando certos aspectos da morfoporosidade e das microestruturas para auxiliar na compreensão da sua evolução e dinâmica relacionada à circulação hídrica, com auxílio de análise de imagens e de microscopia eletrônica de varredura (Castro, 1989a; Castro \& Curmi, 1987; Castro et al, 1993; Santos, 1995; Santos et al, 1992 e 2003).

\section{As interpretações controversas sobre a origem das bandas onduladas no Brasil}

No Brasil, as bandas onduladas, como são mais conhecidas, constituiram denominação sem caráter genético e têm como pioneiro o trabalho da antiga Comissão de Solos (1960) que explicitou sua ocorrência nos então denominados solos Podzolizados de Lins e Marília (hoje Argissolos 
Vermelho-Amarelos, segundo a Embrapa, 1999), embora não tivesse proposto nenhuma interpretação clara sobre sua origem.

Durante a década de 1970, embora dissessem respeito a locais, idades e condições sedimentares bastante diferentes, todas foram relacionadas com o material de origem sedimentar, fossem as estruturas de dissipação (Bigarella, 1974), respeitando-se o termo proposto por este autor uma vez que internacionalmente seriam de retrabalhamento de dunas; fossem as bandas onduladas herdadas do arenito cretáceo, do Grupo Bauru, mas realçadas pela pedogênese, de Suguio \& Coimbra (1976); e ainda, as de Queiroz Neto (1975), como herdadas de coluvionamentos superpostos, argilosos e arenosos, de origem muito recente, concordantes com a topografia dos terrenos atuais e relacionadas à evolução destes. De uma maneira bastante geral, todas elas poderiam ser entendidas hoje como estruturas geogenéticas ou sedimentares singenéticas, como resumidas por Paisani, (2001), ou seja, resultariam de processos deposicionais, independentemente das suas idades e do que lhes sucedeu após sua deposição, ou ainda mistas, no caso das litoherdadas, mas realçadas pela pedogênese.

Num segundo momento, já se encontram os trabalhos bastante recentes, principalmente da década de 1990, relacionados a dois tipos de bandas, ambos de origem pedogenética. O primeiro é relacionado com o que poderíamos denominar de estruturas iluviais ou bandas iluviais ou ainda, estruturas de infiltração das águas de chuva, por secagem da frente de infiltração, e peneiramento relacionado com variações (negativas) na porosidade (às vezes associadas à decantação simples), ou ainda por floculação relacionada a variações no $\mathrm{pH}$ ou presença de íons floculantes, principalmente $\mathrm{Ca}$ e $\mathrm{Mg}$, como proposto por Djikerman et al (1987). Nestas se enquadrariam, por exemplo, as de peneiramento estudadas em Neossolos Quartzarênicos por Rolim \& Santos (1994); Oliveira (1997); Oliveira et al, 1998 e recentemente Furquim (2003).

No entanto, convém ressaltar que no caso estudado por Rolim \& Santos (1994), além da descida das águas por percolação, também se inclui a ascensão do nível freático trazendo finos; e ainda que nos três últimos trabalhos citados, os autores chamam a atenção para o fato das bandas darem origem a horizontes Bt de Argissolos, por coalescência de empilhamentos de estruturas com argila iluvial cimentando grãos de areia. Tais interpretações diferem daquela originalmente proposta (Soil Survey Staff, 1960), pois que as lamelas não se espessam rumo ao topo do perfil, como enfatizado inicialmente, mas sim para a sua base e para jusante, onde originam o Bt por uma espécie de evalescência de bandas empilhadas. Todavia, essa questão permanece nebulosa e necessita ser mais investigada.

Ainda nesse segundo momento, resta um segundo tipo que aqui é denominado de estruturas pedogenéticas e-iluvais. Relacionam-se com a degradação dos horizontes B texturais (ou argílicos) por hidromorfia suspensa, como pioneiramente descrito e apresentado por Queiroz Neto et al (1981), Fernandes Barros (1985) e Castro e Curmi (1987), posteriormente publicado por Fernandes Barros et al (1991), estudando Argissolos desenvolvidos sobre arenitos finos do Grupo Bauru, porém em outro ressalto do Planalto Ocidental Paulista, o Platô de Marília. Apoiados em levantamento dos solos em topossequiências, com base nos procedimentos preconizados por Boulet et al. (1982a, b) e forte apoio de micromorfologia, essas feições foram posteriormente estudadas em detalhe por Castro (1989a); Castro et al (1993); Hallaire et al (1994); Vidal-Torrado (1994); Santos (1995); Cunha (1995); Santos, Castro e Salomão (1996); Cunha et al (1999), e mais recentemente por Paisani (2004), ao reinterpretar as estruturas de dissipação, como já relatado.

A principal razão desta nova interpretação deu-se em conseqüência da constatação da conexão das bandas onduladas ao horizonte Btg através de semi-arcos projetados para jusante, denominados de pendúculos, fato jamais relatado na literatura. Os estudos morfológicos detalhados em campo, em trincheiras longas contemplando toda sua trajetória, desde seu aparecimento até o desaparecimento, bem como dos horizontes relacionados, valorizaram as transições entre bandas e seu entorno, e, sobretudo as características micromorfológicas de amostras dessas bandas, interbandas e horizontes associados (Bt, Btg e E) permitindo a descoberta das evidências de filiação genética entre eles.

Esses estudos ainda revelaram a presença de duas estruturas iluviais distintas no interior das bandas, mais notáveis no pedúnculo e na sua trajetória inicial quando ainda conectadas ao Btg: uma na base, que guarda sinais de herança deste horizonte resultante de iluviação, apresentando revestimentos caulinítico-ferruginosos de macroporos, bloqueando-os, com sinais de segregação pósdeposicional do ferro por hidromorfia e de dispersão das caulinitas, resultando em feições iluviais zonadas, laminadas e microlaminadas (como também descrito em Bullock et al, 1985); e outra sobrejacente a esta, de iluviação, porém sem evidências de segregação, a qual permanece exclusiva da trajetória final das bandas conectadas, bem como nas bandas suspensas, como descrito detalhadamente por Castro \& Curmi (1987) e Castro (1989). Castro et al (1993) e Hallaire et al. (1994), ao caracterizarem também a evolução da sua morfoporosidade. Detalhes de uma trincheira longa onde as bandas estão conectadas, além das características da morfoporosidade podem ser vistas em Castro (1999) e da porção entre a base de uma banda conectada e o topo do horizonte Btg podem ser vistas em Fernandes Barros et al (1991). 
Castro (1989a), utilizando microscopia eletrônica de transmissão, de varredura e microanálise, também identificara micro-caulinitas revestindo discordantemente as feições iluviais anteriores segregadas nos macroporos e mesmo as pontes ou películas residuais de argila não iluvial entre os grãos primários ou envolvendo-os, paralelamente a um aumento de $\mathrm{pH}$ e do $\mathrm{Ki}$ (relação $\mathrm{SiO}_{2} / \mathrm{A}_{1} \mathrm{O}_{3}$ ), além de, traços de esmectita aluminosa e de ilita na argila do topo do Btg e para jusante, bem como na base das bandas conectadas. Para a autora eram evidências que confirmavam a atuação de ciclos de fluxos verticais e laterais que conduziam à degradação e recomposição das caulinitas associadas ao processo de transformação pedológica lateral dos Latossolos em Argissolos.

A mesma autora ainda constatou predomínio de porosidade cavitária de dissolução do plasma inicial nesse meio hidromórfico da base das lamelas e no topo do Btg, responsável pela instabilização do plasma e sua subseqüente remoção, seguida de concentração residual de areia acima delas, formando o horizonte E, seja interlamelas, seja acima delas. A autora relacionou as feições iluviais das lamelas ao fenômeno de peneiramento (ainda que na época tenha preferido utilizar os termos de decantação simples) na parte superior, as quais eram também de decantação na parte inferior das mesmas, mas de ciclo anterior posteriormente hidromorfizadas. No Bt esse fenômeno se repetiria, aprofundando-o à medida que a remoção prosseguia. Assim, vários volumes de areia lavada se formavam e evoluíam para grandes bolsões, cujo "teto" corresponderia a uma banda conectada, ainda preservando as características do Btg. Mas, abaixo dela, onde a saturação seria maior, levando à dissociação ferro-argila e à sua lessivagem e lixiviação, respectivamente, num contexto de eluviação (da argila e do ferro), acumulava-se a areia esbranquiçada ("lavada").

Com o prosseguimento do processo, a parte da extremidade jusante acabaria se rompendo, dada a energia da circulação e aumento das poro-pressões, gerando a configuração em semi-arco que as lamelas mantém e as duas estruturas de acumulação superpostas, daí a denominação de estruturas de acumulação dupla e a interpretação de eiluviação para o conjunto das lamelas e dos horizontes Btg e E relacionados, atribuídas à redistribuição e perda de matéria.

Finalizando, a mesma autora acrescenta que, com a degradação final das lamelas, à medida que o Btg se aprofundava, a parte montante das lamelas também se desconectaria do Btg, concomitantemente à eluviação da parte inferior da própria banda, resultando em bandas mais finas, suspensas e amareladas ("descoloridas") na massa arenosa, de concentração residual. Pelo exposto, a degradação das lamelas para jusante dependeria diretamente dos fluxos hídricos laterais, da hidromorfia e da eluviação, esta mais forte que a iluviação, incapaz de recuperar as perdas.
Quanto à presença de fluxos hídricos suspensos acima delas (Fernandes Barros et al 1991; Manfredini \& Queiroz Neto, 1993; Salomão; 1994; Santos, Castro e Salomão, 1996) e, por se restringirem a uma espécie de faixa que contorna a borda do platô, foram consideradas indicadoras da sua evolução geomorfológica (Pellerin \& Queiroz Neto,1992 a,b; Salomão,1994), constituindo zonas onde as transformações pedogenéticas laterais instabilizam os solos e por isso favorecem a dissecação do relevo, corroborando a interpretação original de Castro (1989a), ainda que fenômeno parecido "prepare" (fragilidade) o material arenoso (Neossolos Quartzarênicos) para a dissecação dos interflúvios (Oliveira, 1997, Oliveira, Castro e Ferreira,1998)

Pelo exposto, e quanto à origem essencialmente pedogenética, Ruellan \& Dosso (1993), que também preferem chamar essas feições de bandas onduladas, as classificam em dois tipos quanto à sua origem: uma exclusivamente iluvial relacionada à translocação de finos, sobretudo argilas, pelas águas percolantes, sob mecanismos de infiltração, peneiramento, floculação; e outra, de e-iluviação, relacionada com o processo de transformação pedológica lateral dos Latossolos em Argissolos, em particular do horizonte Bt em E, por hidromorfia suspensa.

Esta última interpretação vem motivando a reflexão sobre o significado geomorfológico das bandas, em termos da evolução das vertentes, mas, em princípio, poderiam ser tomadas como indicadoras de instabilidade atual dos materiais pedológicos em vertentes igualmente instáveis de interflúvios dissecados.

\section{A formação dos Argissolos e sua relação com o relevo e as bandas onduladas}

Os Argissolos, segundo a Embrapa (1999), correspondem a uma classe de solos constituída por material mineral, com presença de horizonte $\mathrm{B}$ textural (Bt) diagnóstico, imediatamente abaixo do horizonte $\mathrm{A}$ ou $\mathrm{E}$, argila de atividade baixa, que se subdivide em subclasses devidas às variações morfológicas e dos constituintes. O Argissolo VermelhoAmarelo é uma das subclasses dos Argissolos e se distingue, sobretudo, pela cor que lhe empresta o nome.

Revisões relativamente recentes a respeito da formação dos Argissolos, em particular dos seus horizontes Bt, podem ser encontradas em Castro (1989a), Moniz (1992), VidalTorrado et al (1999) e Cooper et al (2002). Em síntese, as origens dos horizontes argilosos do tipo Bt subjacentes aos horizontes E (com ou sem bandas onduladas), são bastante conhecidos da literatura pedológica onde se atribui sua origem, tradicionalmente, à argiluviação (Soil Survey Staff, 1960, 1975; Comissão de Solos, 1960; Buol, 1983; Embrapa, 1987, 1999; Jacomini, 2005). Porém, esta convive com outras interpretações, embora menos numerosas na literatura, como 
adensamento por dessecação (Chauvel, 1976; Moniz \& Buol, 1983), seguida de iluviação restrita ao topo desse horizonte (Castro, 1989a), herança de coluvionamentos recentes sucessivos (Penteado \& Ranzani, 1973) ou de substrato lamítico intercalado a arenitos cretáceos, admitindo-se concomitantemente a formação de argila por transformação por perda de sílica e bases de minerais primários (Rueda \& Dematté, 1988). Novamente a questão esbarra ou na herança do substrato rochoso ou em produto essencialmente de pedogênese.

A interpretação mais recente é aquela que vem juntamente com os trabalhos que também aprofundaram o estudo das bandas onduladas, onde os horizontes Btg são atribuídos à degradação por eluviação que remove e destrói o material argiloso, originando o horizonte E, associadamente a condições de redução devida a encharcamento suspenso temporário na transição E/Bt (Castro, 1989a; Fernandes Barros, 1985; Queiroz Neto et al, 1981; Soubiés \& Leprun, 1986), corroborando grande parte das idéias de Bullock \& Thompson (1985).

No Brasil, os Latossolos são claramente associados a relevo plano a suavemente ondulado e relacionado, sobretudo, a antigas superfícies de aplainamento, pedimentos ou terraços fluviais antigos, onde a latolização ou ferralitização seria muito avançada (Embrapa, 1999). Já os Argissolos são comumente associados a relevo de moderado à forte ondulado, cuja evolução pedogenética é caracterizada por ferralitização incompleta, em conexão com paragênese caulinítica-oxídica ou virtualmente caulinítica, de baixa atividade (Embrapa, 1999).

Estudos realizados por Pellerin \& Queiroz Neto (1992 a, b), Salomão (1994), Santos (1995 e 2000) e Vidal-Torrado et al (1999), dentre outros, em regiões tropicais úmidas com estações contrastadas, chamaram a atenção para o fato de que os Argissolos se encontram freqüentemente associados a relevo dissecado, com maior densidade e grau de entalhe da rede de drenagem e maior declive que os Latossolos que restam a montante. Mas o fato é que ainda pouco se sabe sobre os mecanismos que se desenvolvem nessas sucessões laterais de solos, do ponto de vista do relevo e das correlações morfopedológicas, como permitem os sistemas pedológicos (Boulet et al, 1984), embora na década de 1980 tenha sido tentada uma síntese sobre os sistemas encontrados no Brasil (Soubiés \& Leprun, 1984), mais tarde retomada por Queiroz Neto (2000) e suas relações com a evolução do modelado.

Nesse aspecto o papel dos fluxos laterais nos interflúvios, as mudanças de solos e a transformação e/ou neoformação de constituintes há muito já vem merecendo destaque na literatura, pelo menos desde a década de 1960, a partir da retomada das idéias de Milne (1938), por vários autores e graças aos avanços nos métodos e técnicas de estudo (Vidal-Torrado et al, 2005). Inclusive já havia sido esclarecido que a instabilização dos solos relacionada a tais fluxos é descendente, mas a(s) nova(s) pedogênese(s) evolui (em) remontantemente como lembram Queiroz Neto (2000 e 2004) e Vidal-Torrado et al (2005). Por outro lado, Pellerin \& Queiroz Neto (1992 a,b) e Queiroz Neto (2000, 2004), lembram também que os processos erosivos penecontemporâneos resultaram no preenchimento do fundo dos vales revelando, assim, que a evolução geomorfológica e pedogenética é contemporânea e interdependente ("solidária" nos termos desse último autor), contrariamente ao paradigma dominante na literatura desde a década de 1970 , baseadas nas teorias geomorfológicas clássicas, ou ainda baseadas no empilhamento de colúvios, como materiais de origem do Bte do próprio E como relatado. Além disso, são vários os modelos geomorfológicos evolutivos propostos na literatura, o que dificulta a adoção de um único como universal, tornando necessários mais estudos de detalhe e metodologicamente mais completos (Vidal-Torrado et al, 2005).

Assim, ainda não é possível finalizar uma teoria completa sobre o assunto, embora os estudos de caso, desde os estudos pioneiros realizados na África, na Guiana Francesa, na Amazônia e no Sudeste do Brasil, sobre o sistema Latossolo-Argissolo ou similar, já permitam considerar dois grupos principais de possibilidades, ambas como resposta a reajustes hidráulicos atuantes sobre a cobertura latossólica inicial que resta residual nos topos dos interflúvios, desde que sem truncamentos erosivos:

I - quanto às condições ambientais dos desequilíbrios hidráulicos indutores (motor) das transformações pedológicas, podem-se resumir a praticamente três: (1) ciclos de umectação/dessecação, ligados a sazonalidade climáticacontemporânea, própria de climas tropicais úmidos com estações contrastadas, onde é comum a ocorrência desses solos justapostos (sucessões laterais); (2) oscilações climáticas mais secas e mais úmidas ocorridas durante o Quaternário (paleoclimas); (3) movimentos tectônicos recentes conduzindo a aprofundamento do nível dos talvegues, embora pouco discutidos em pedologia;

II - quanto aos mecanismos da transformação pedológica lateral em si, resultariam: (1) de adensamento $(\mathrm{Bw} \rightarrow \mathrm{Bt})$; (2) de iluviação $(\mathrm{E} \rightarrow-\mathrm{Bt})$, ou (3) de adensamento, seguido de hidromorfia suspensa (Btg) de e-iluviação (Btg'! E), onde a eluviação seria mais potente e eficaz do que a iluviação, devido esta não recuperar as perdas laterais; em todo caso, seja quanto ao motor, seja aos processos, tratarse-ia de resposta associada à evolução geomorfológica dos interflúvios e dos solos de suas próprias vertentes, onde a circulação vertical e lateral diferenciada de soluções que mobilizam, transportam e redistribuem materiais (pedoturbação) se associam ao desequilíbrio hidráulico dos interflúvios e podem remontar progressivamente nas vertentes, por auto-desenvolvimento como proposto originalmente por Bocquier (1973).

Embora os sistemas pedológicos de transformação 
lateral das regiões tropicais úmidas e subúmidas possam ser de vários tipos, como proposto por Boulet et al (1984), dentre eles os e-iluviais, onde é clara a filiação genética entre os solos de montante e jusante, como seria o caso da sucessão lateral Latossolo-Argissolo sem truncamentos erosivos, pode-se pensá-la ainda como resposta morfopedológica, isto é, resultante da própria evolução geomorfológica e pedogenética interdependente. Queiroz Neto $(2000,2004)$, nesse sentido, defende essa idéia, a qual denomina de evolução "solidária" e valoriza os estudos em continuum (topossequiências) (Boulet et al, 1982; Boulet, 1988, 1992) como método de campo, na escala dos interflúvios, portanto dos sistemas pedológicos, e não através de perfis isolados e representativos do core de superfícies geomórficas escalonadas como tradicionalmente se faz. Para estudo das relações morfogênese $\mathrm{x}$ pedogênese, as abordagens multiescalas e multi-temas (constituindo uma forma própria de approach), são particularmente recomendadas (Castro, 1989 a, Vidal-Torrado et al, 2005).

No que se refere às vertentes relacionadas aos Argissolos, quaisquer que sejam o relevo e o substrato rochoso, ainda resta destacar as rupturas de declive que, de modo geral, podem aparecer no topo ou nas vertentes e marca, com frequiência, o aparecimento desses solos. Sua origem tem sido associada comumente a descontinuidades litoestruturais, a lineamentos estruturais e outras causas relacionadas à dissecação erosiva. Já as rupturas côncavas de fraco declive, quase imperceptíveis nas vertentes suavizadas, além de terem sido bem pouco estudadas, menos ainda o são quando relacionadas espacial e funcionalmente a sistemas de transformação pedológica lateral de coberturas latossólicas em argissólicas.

De posse dessas idéias, o estudo desenvolvido no Platô de Bauru, sobre colina média representativa, buscou as evidências das estruturas presentes na escala macro e micromorfológica, bem como as características físicohídricas, como detentores de parâmetros indicadores dos possíveis mecanismos de formação das lamelas e do horizonte Bt relacionado, no contexto da evolução da vertente.

\section{A área de estudo}

A área de estudo escolhida situa-se no oeste do Estado de São Paulo, sustentada por rochas da Bacia Sedimentar do Paraná, cujo relevo, bastante suavizado, é relacionado aos acamamentos sub-horizontais, predominantemente de arenitos, com leve caimento para oeste, formando uma extensa superfície nivelada em cotas médias próximas de 500 $\mathrm{m}$ de altitude, frequentemente interpretada como originada de denudação pós-cretácica e relacionada à umidificação progressiva do clima tropical, denominada Província Geomorfológica do Planalto Ocidental Paulista
(Almeida,1964; Ab’Sáber, 1969). Alguns ressaltos topográficos sobressaem nessa paisagem monótona, na forma de platôs residuais, às vezes de beleza cênica notável, cuja origem se relaciona a fatores locais de resistência, em geral de natureza litológica e/ou estrutural. Dentre eles, o chamado Platô de Bauru é um dos mais dissecados e rebaixados, compondo um conjunto de colinas amplas e médias, que no seu quadrante sudoeste transiciona para uma zona de escarpas e morrotes (Salomão, 1994) (Figura 1). Nas colinas médias desse Platô desenvolvem-se Argissolos, cujo horizonte $\mathrm{E}$ arenoso apresenta numerosas lamelas, ora conectadas ao horizonte subjacente, ora desconectadas e suspensas no seio da massa arenosa. Sua origem, evolução e relações com a evolução do modelado carecem de investigação, mas o fato que chama a atenção é que se situam nos segmentos côncavos intermediários dessas colinas médias, cujos topos e bases são convexizados.

O substrato geológico do Platô de Bauru é dominado por rochas areníticas do Grupo Bauru (Cretáceo), sobretudo da Formação Marília, entremeado por diques e sills de rochas vulcânicas da Formação Serra Geral (Eo-Cretáceo). A Formação Marília se constitui de bancos de arenitos de granulação fina a muito fina, róseo a castanho, estratificação cruzada, com espessuras variando entre 2 a 20 metros, alternada com bancos de lamitos, siltitos e arenitos lamíticos de cor castanho-avermelhado, maciços ou com acamamento plano-paralelo grosseiro, freqüentemente com marcas de microestratificação cruzada. Pode apresentar nódulos carbonáticos característicos que aparecem dispersos nos sedimentos ou concentrados em níveis ou zonas, sendo o cimento carbonático também muito freqüente (Soares et al., 1980).

O clima é do tipo tropical úmido, Cwa conforme a conhecida classificação de Koëppen (1948), com duas estações bem definidas, uma seca (maio-setembro) e outra chuvosa (outubro-abril), o que lhe atribui características de mesotérmico de inverno seco. A precipitação anual fica ao redor de $1500 \mathrm{~mm}$, a temperatura média do mês mais frio é de $20^{\circ} \mathrm{C}$ e a do mês mais quente de $27^{\circ} \mathrm{C}$ (Salomão, 1994).

A vegetação primária era a Floresta Latifoliada Tropical com inclusões de Cerrado, substituída pela cultura do café iniciada na década de 1920, sucedida por pastagens e culturas de subsistência, restringindo o café aos topos, como se encontra atualmente. O perfil estudado encontra-se em área de pastagem degradada próxima à zona de expansão urbana da cidade de Bauru, numa localidade denominada de Pousada da Esperança.

Dois dos compartimentos morfopedológicos mapeados por Salomão (1994) chamam a atenção. O primeiro chamado de colinas amplas é dominante na sua porção central, devido presença de topos suavemente convexos cobertos por Latossolo Vermelho espesso e argiloso e de vertentes longas (em geral $>1000 \mathrm{~m}$ ), de baixo declive $(40 \%)$, que passam 


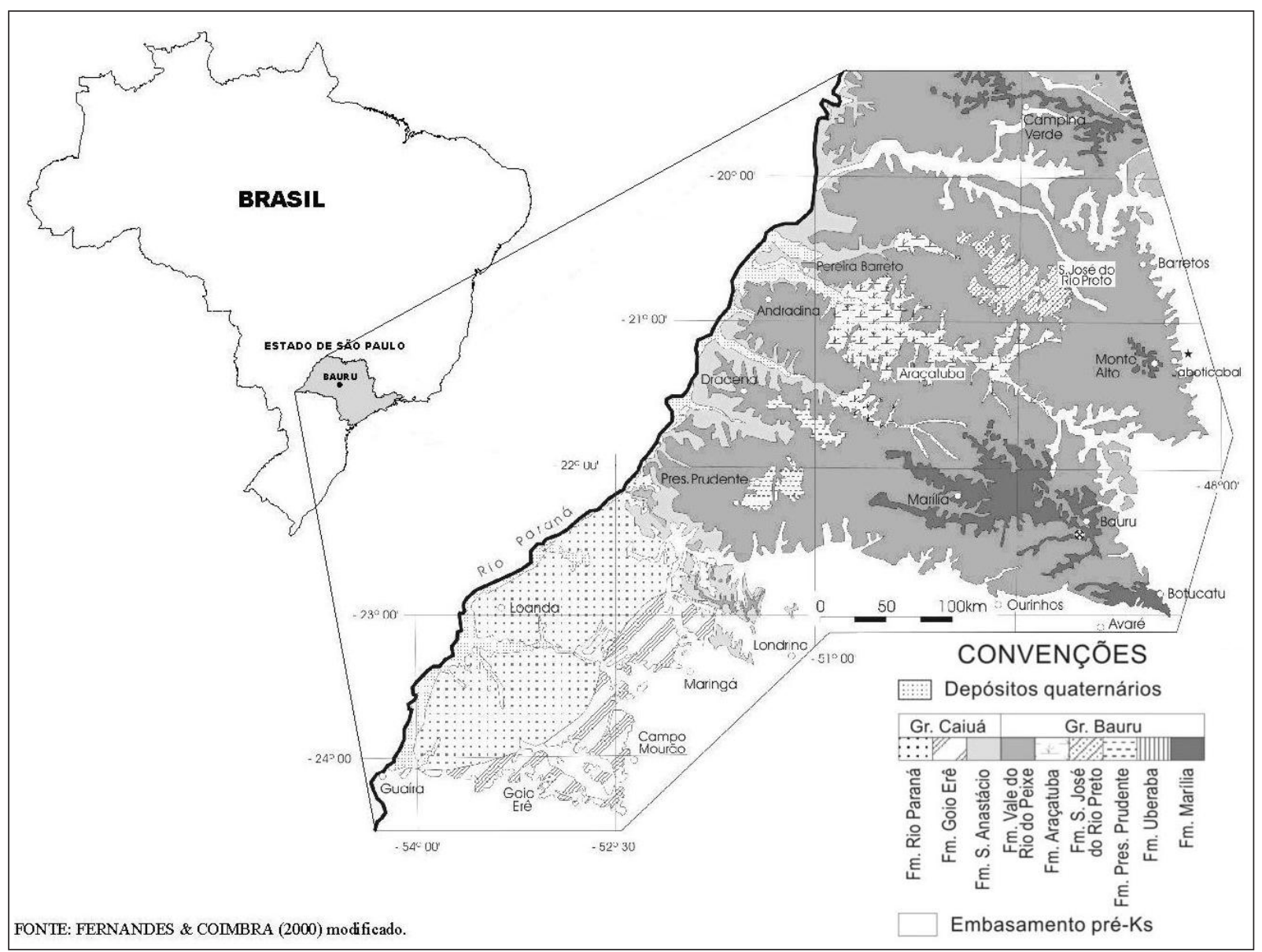

Figura 1 - Localização da área de estudo

lateralmente nas vertentes ao Latossolo Vermelho Amarelo argilo-arenoso. O segundo tipo, denominado de colinas médias, predomina nas bordas do referido Platô, sobretudo a noroeste e oeste, com declives em geral $>15 \%$, cujas formas são mistas, convexo-côncavo-convexas, as vertentes mais curtas $(<1000 \mathrm{~m})$ e relacionadas a uma sucessão lateral de solos fortemente diferenciada, constituída por Latossolo Vermelho Amarelo nos topos e terços superiores, Argissolos nos segmentos médios e Gleissolos nos sopés, este com horizontes húmicos e até hísticos e às vezes soterrados por colúvios e alúvio-colúvios bastante recentes (Figura 2), interpretada como sistema pedológico de transformação lateral do tipo e-iluvial (Boulet et al, 1984) e como correlativo da configuração pós-cretácica das colinas médias (Santos et al, 1992; Salomão, 1994, 1999; Santos, 1995).

OArgissolo Vermelho Amarelo do Platô de Bauru chama a atenção por vários motivos: apresenta numerosas lamelas (também conhecidas como bandas onduladas) no horizonte eluvial (E) que aparecem ora conectadas ao horizonte B hidromórfico subjacente (Btg), ora desconectadas e suspensas na massa arenosa daquele horizonte; pela topografia das lamelas, do Btg e do próprio Bt ser relativamente concordante com a topografia atual da vertente; e pelas lamelas e horizonte Btg apresentarem estruturas e constituição similares entre si. Características similares foram encontradas também no oeste do estado de São Paulo, em outro platô residual do Planalto Ocidental Paulista, como no Platô de Marília (Castro, 1989a; Pellerin \& Queiroz Neto, 1992 a, b), em vários platôs localizados no Noroeste do estado do Paraná sustentados também por arenitos, porém da Formação Caiuá, mas igualmente do Cretáceo, e do mesmo Grupo Bauru (Cunha et al, 1999; Nakashima , 2004) ou ainda sobre arenitos mais antigos, datados do Permo-Carbonífero, integrantes da mesma Bacia Sedimentar do Paraná, mas situados na Província Geomórfica da Depressão Periferia Paulista, no estado de São Paulo (Vidal-Torrado et al, 1999). Portanto, sua formação parece associada a materiais arenosos e areníticos, todos sedimentares, independentemente de sua idade e compartimento geomorfológico onde se situam. 


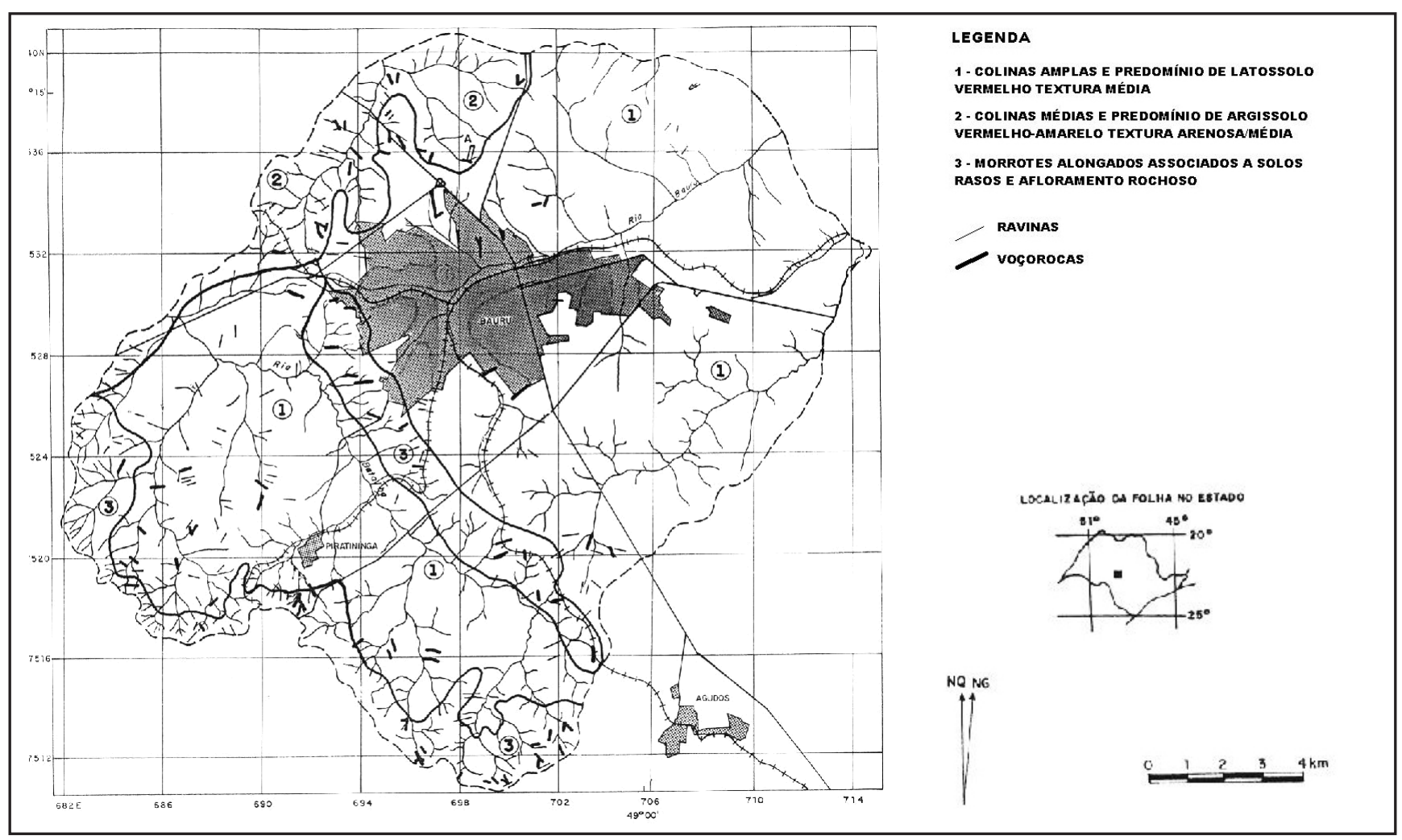

Figura 2 - Compartimentação morfopedológica da bacia do Rio Bauru/SP - (Adaptado de Salomão, 1994)

O Latossolo Vermelho situado no terço superior apresenta estrutura em blocos nos horizontes superficiais e maciça granular pequena (microagregada), em profundidade, no horizonte $\mathrm{Bw}$, o qual, a partir do terço médio para jusante, desenvolve estrutura em blocos pequenos a médios e progressivamente grandes e mais fortes até se tornar um $\mathrm{Bt}$ constituindo um horizonte diagnóstico do Argissolo Vermelho-Amarelo, mantendo um horizonte Bw em sua base, abaixo do Bt. Este apresenta hidromorfia no topo,originando um subhorizonte Btg. À jusante, o Btg se torna progressivamente mais hidromórfico até próximo à base do terço inferior onde cede lugar ao Gleissolo Háplico. Dentre as variações morfológicas encontradas na toposseqüência destaca-se a passagem do horizonte $\mathrm{Bw}$ para $\mathrm{Bt}$ no terço superior para o médio e deste para Btg, seguindo-se o E com aparecimento de bandas onduladas cada vez mais nítidas e estruturadas, conectadas e desconectadas, como já relatado. $\mathrm{O}$ perfil de Argissolo estudado corresponde àquele exposto no perfil de solo da Trincheira 4 (T4) (Figura 2).

\section{Materiais e métodos}

O perfil de Argissolo selecionado (Figura 3) teve descrição morfológica dos horizontes segundo as recomendações gerais adaptadas de Lemos \& Santos (1984), e mais detalhada para as transições entre horizontes, aos horizontes relacionados às bandas, às transições superiores e inferiores das bandas e à coleta das bandas onduladas. Estas obedeceram ao critério de aparecimento, de progressão e de desaparecimento, bem como do volume situado abaixo do pedúnculo das bandas onduladas. Procedeu-se ainda à observação detalhada das características morfológicas ao longo da trajetória lateral do Btg e Bt, dos volumes interbandas e das bandas suspensas como procedera Castro (1989a). As amostras foram coletadas de modo convencional para análises granulométricas e indeformadas (com estrutura de campo conservada), para ensaios físico-hídricos de retenção e condutividade hidráulica saturada, em anéis volumétricos de $300 \mathrm{~cm}^{3}$ contendo três cilindros de $100 \mathrm{~cm}^{3}$ (Klute,1986) e estudo micromorfológico (caixas de papel cartão de 9x13x4 cm) (Castro, 1989b; Castro et al, 2003).

A análise granulométrica foi realizada no Institut de Recherche pour le Développement (IRD) de Cayenne (Guiana Francesa), pelo método da pipeta de Robinson. A escala textural utilizada foi de areia grossa $(2-0,2 \mathrm{~mm})$; areia fina $(0,2-0,05 \mathrm{~mm})$; silte $(0,05-0,002 \mathrm{~mm})$ e argila $<0,002 \mathrm{~mm}$. Os ensaios físico-hídricos foram feitos no Laboratório de Física do Solo e Irrigação do Instituto de Pesquisas Tecnológicas (IPT) do Estado de São Paulo, por meio do registro da condutividade hidráulica saturada (Ksat) e daretenção de água (para o cálculo da macro e microporosidade) com auxílio 


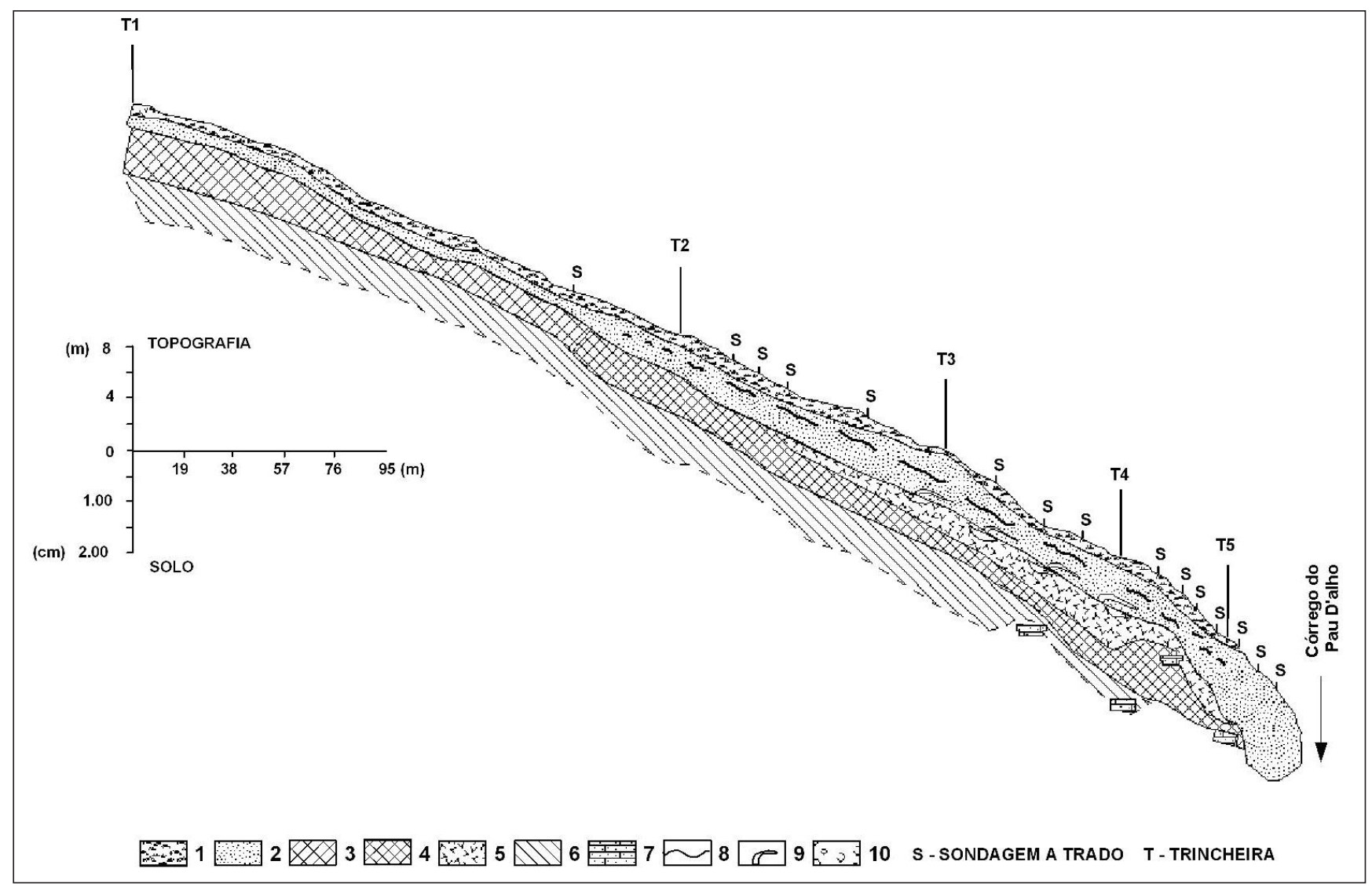

Figura 3 - Topossequência estudada: (1) horizonte A; (2) horizonte E; (3) horizonte Bw com estrutura em blocos; (4) horizonte Bt; (5) horizonte Btg; (6) horizonte Bw com estrutura maciça; (7) alterita; (8) bandas onduladas suspensas; (9) bandas onduladas ligados ao horizonte $\mathrm{Bt}$; (10) bolsões arenosos.

das câmaras de Richards (Klute, 1986). Para Ksat adotou-se o método da carga constante para uma coluna de solo com área de seção transversal uniforme, saturada por capilaridade e submetida a uma carga hidráulica de $7 \mathrm{~cm}$ durante 24 horas, após o que se mediu o volume de água percolada em 30 minutos. Os anéis $\left(100 \mathrm{~cm}^{3}\right)$ foram levados à câmara de Richards e submetidos a médias e altas tensões $(0,1$ a 15 atm.).

A porosidade foi obtida inicialmente a partir das amostras dos cilindros de $300 \mathrm{~cm}^{3}$ previamente saturadas e posteriormente submetidas a tensões entre 0,05 e $0,1 \mathrm{~atm}$ utilizando-se funis de placa porosa, de acordo com os procedimentos citados por Libardi (1984). Os poros foram classificados em microporos $(<30 \mu \mathrm{m})$ e macroporos $(>30 \mu \mathrm{m})$, sendo a microporosidade determinada a partir do volume de água retido na amostra do solo submetida à tensão de $60 \mathrm{~cm}$ de $\mathrm{H}_{2} \mathrm{O}$ e a macroporosidade determinada subtraindo-se o teor de água do solo $\left(\mathrm{cm}^{3} / \mathrm{cm}^{3}\right)$, no ponto de saturação, do teor de água do solo submetido à tensão de $60 \mathrm{~cm}$ de $\mathrm{H}_{2} \mathrm{O}$. A porosidade total do solo foi determinada a partir do valor da umidade volumétrica equivalente ao ponto de saturação (potencial matricial nulo).

No estudo micromorfológico utilizou-se microscópico óptico polarizante petrográfico para exame de lâminas delgadas das amostras previamente impregnadas com resina de poliéster, posteriormente cortadas e polidas (resumido in Castro, 1985), onde foram observadas as principais microestruturas pedológicas, desde a escala milimétrica $(\mathrm{mm})$ até a escala micrométrica $(\mu \mathrm{m})$. A descrição baseou-se nas definições e nos critérios de identificação propostos por Brewer (1976), Stoops \& Jongerius (1975) e sintetizados por Bullock et al. (1985), adaptados para o português por Castro (1989b) Considerou-se fundo matricial ao conjunto dos constituintes; plasma à fração granulométrica igual/menor a $2 \mu \mathrm{m}$; esqueleto à fração granulométrica compreendida entre 2 e $2000 \mu \mathrm{m}$ e macroporos (de diferentes diâmetros e formas a partir de $20 \mu \mathrm{m}$ de diâmetro). Adotou-se o modelo de freqüência de objetos em campo visual de Fitzpatrick (1980) para cálculo da distribuição relativa dos constituintes. A identificação das microestruturas baseou-se nos conceitos a seguir: 
- estruturas plásmicas: arranjo espacial das partículas da fração argila, entre si, segundo diferentes direções; sua identificação permitiu interpretar sua origem, se iluvial (associadas às paredes de poros ou de agregados, com orientação forte e contínua) ou se resultantes de esforços e tensões (com orientação estriada, sem relação direta com as paredes acima mencionadas);

- estrutura de base: arranjo espacial entre plasma, esqueleto e poros (fundo matricial). Adotou-se a classificação de Stoops \& Jongerius (1975) que distinguem: porfírica partículas maiores (areia) distribuídas numa matriz de partículas muito finas (argila), podendo ser aberta, dupla e simples (dependendo da proporção entre as partículas); gefúrica - partículas maiores ligadas por braços ou pontes de materiais mais finos; enáulica - esqueleto e agregados de material mais fino nos poros intersticiais, sem preenchê-los totalmente; quitônica - esqueleto rodeado de material fino (areia ou agregados envolvidos por argila) e mônica esqueleto em grãos simples. A identificação dessas estruturas permitiu reconhecer os processos pedogenéticos ligados à agregação e/ou à desagregação dos componentes.

As feições pedológicas microscópicas foram denominadas de cutãs (revestimentos de películas argilosas) - modificações de textura e estrutura nas superfícies do material pedológico, resultante de concentração de certos constituintes (cutãs de iluviação) com ou sem segregação pós-(deposicional) (zonadas, microlaminadas), ou a modificações in situ do plasma por reorientações ligadas a esforços e tensões (cutãs de estresse), ou ainda transformações mineralógicas (cutãs de transformação). Sua identificação permitiu reconhecer a presença ou não de fenômenos de iluviação, de segregação pós-deposicional ligada à hidromorfia, bem como os constituintes relacionados (principalmente caulinita e ferro) (Santos et al., 2004).

Os resultados obtidos no estudo morfológico e micromorfológico foram correlacionados aos resultados granulométricos e hídricos, com o objetivo de verificar a convergência de dados, indicadores das evidências de perdas, transformações e deposições de constituintes.

\section{Resultados}

\subsection{Macromorfologia}

A descrição morfológica do perfil de solo estudado (T4) revela a presença de 05 horizontes pedológicos superpostos: A, E com bandas onduladas, Btg (topo hidromórfico do Bt) com bolsões arenosos, Bt e Bw, sendo que apenas os quatro primeiros foram descritos e analisados no presente trabalho devido à ênfase dada às bandas onduladas e horizontes associados. Abaixo do Bw aparece o arenito alterado da Formação Marília (Figuras 4 e 5).

São descritas a seguir as características de campo de cada horizonte

São descritas a seguir as características de campo de cada horizonte:

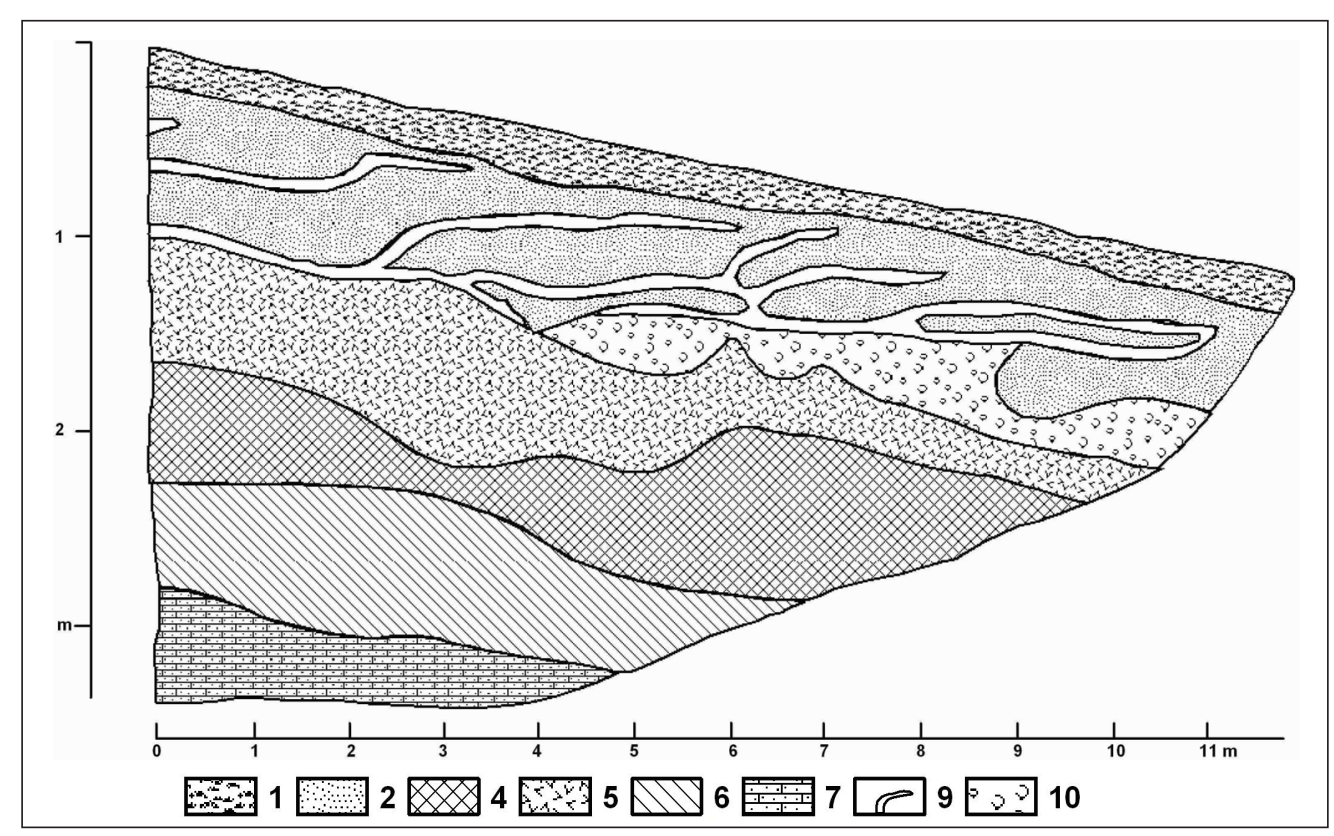

Figura 4 - Perfil de solo estudado (Trincheira 4): (1) horizonte A; (2) horizonte E; (4) horizonte Bt; (5) horizonte Btg; (6) horizonte Bw com estrutura maciça; (7) alterita; (9) bandas onduladas; (10) bolsões arenosos. 


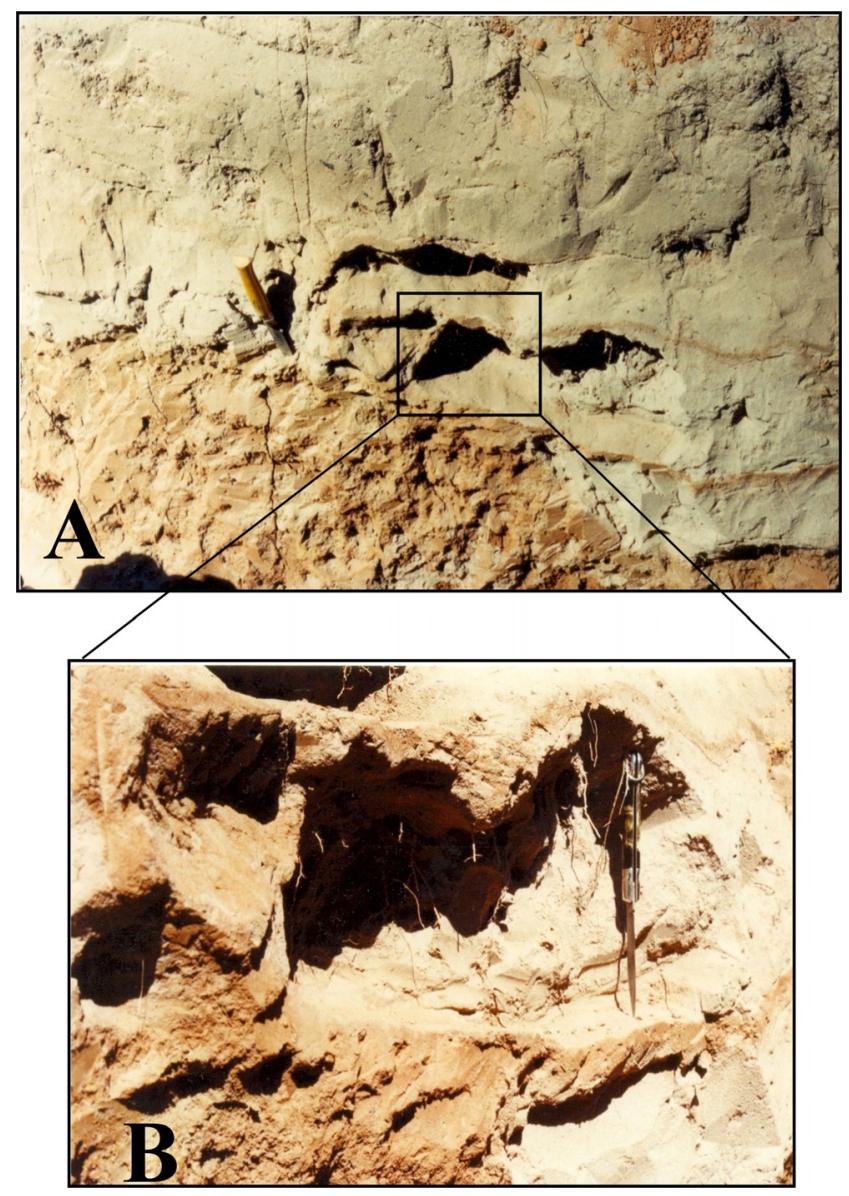

Figura 5 - Bandas onduladas no seio do horizonte E (A) e detalhe do nascimento das bandas onduladas no horizonte Btg (B).

Horizonte A: 0-9 cm, cor bruno avermelhado (5YR 3/ 3 ), arenosa, blocos pequenos a médios subangulares de 1 $\mathrm{cm}$, friável, presença de volumes milimétricos de areia lavada, raízes fasciculadas finas abundantes, porosidade intergrãos e interagregados dominantes, bem desenvolvidas, transição clara e ondulada.

Horizonte E: 10-88 cm, cor bruno amarelado (10YR 5/ 3), arenosa, granular, maciço, menor presença de raízes fasciculadas finas com distribuição irregular, porosidade intergrãos principal e tubular secundária, transição clara e ondulada. Observou-se a presença de numerosas bandas onduladas conectadas e desconectadas de cor vermelhoamarela (rever Figura 5).

As lamelas superiores são desconectadas do Bt, são mais finas $(1-3 \mathrm{~cm})$, amareladas, areno-argilosas e estão suspensas na massa arenosa do horizonte arenoso E, intercaladas de volumes arenosos esbranquiçados (interbandas). As lamelas inferiores são mais espessas (em geral 5 ou $6 \mathrm{~cm}$ ), argilo-arenosas, mais avermelhadas e estão conectadas ao horizonte Btg subjacente por um pedúnculo em forma de semi-arco projetado para jusante, geralmente com menos de $10 \mathrm{~m}$ de extensão, às vezes anastomosados com outras abaixo ou acima, entre as quais aparecem bolsões arenosos esbranquiçados, no topo do Btg, Vários pedúnculos se sucedem lateralmente para jusante em todo trecho médio da vertente, a intervalos pequenos e relativamente regulares (cerca de 5 a $10 \mathrm{~m}$ de intervalo. Entre essas bandas e o topo do Btg, bem como na base das bandas espessas, ocorrem numerosas relíquias deste horizonte (pedorrelíquias), subcentimétricas e milimétricas, mais escuras e arredondadas, as quais são menos numerosas e menores nas interbandas sobrejacentes.

A observação detalhada das lamelas permitiu constatar que as lamelas desconectadas são mais finas (3 a $4 \mathrm{~cm}$ ) e assemelham-se às características da trajetória final das bandas conectadas. Entre as bandas conectadas e o topo do Btg aparecem numerosas relíquias destas, esparsas, milimétricas e arredondadas. Nos volumes interbandas suspensas, as relíquias praticamente desaparecem. Já as conectadas apresentam manchas de hidromorfia na sua base, de cor cinza (10YR 4/6) a bruno amarelado (2,5YR 6/4), são franco-argilosas, com blocos subangulares pequenos de coesão fraca a montante (nascimento das bandas no horizonte Btg) e tendência maciça para jusante, quando se tornam também descoloridas. No geral apresentam limites superiores mais nítidos, contínuos e planos e cores mais claras, embora no mesmo matiz. Os limites inferiores são irregulares e ondulados apresentando interpenetração (papiliformes segundo Fernandes Barros et al., 1991) e também reproduzem a mesma cor e evidência de hidromorfia do Btg. Sua espessura varia de 6 a $10 \mathrm{~cm}$ no pedúnculo e diminui progressivamente até desaparecerem lateralmente, por dissipação total, isto é, eluviação total e transformação emE.

Horizonte Btg: 89-158 cm, cor vermelho (2,5YR 4/6), com mosqueamento cinza (10YR 4/6) abundante a bruno amarelado (2,5YR 6/4), franco argilosa, blocos subangulares grandes, ligeiramente duro, porosidade tubular fina ( $>1 \mathrm{~mm})$ com revestimento argiloso em algumas paredes (cerosidade), transição difusa e ondulada. Na porção superior deste horizonte observou-se a presença de bolsões arenosos, centimétricos com forma subarredondada, cor vermelha (2,5YR 4/6) e mosqueamento cinza (2,5YR 4/6), todos com estrutura maciça. Abaixo dos pedúnculos das bandas o Btg apresenta maior espessura e forma lenticular.

Horizonte Bt: 159-214 cm, cor vermelho (2,5YR 4/6) homogênea, franco-argilosa, blocos subangulares grandes fortes a moderado em profundidade, ligeiramente duro passando a maciça em profundidade e porosidade fissural fina moderada e tubular fina $(>1 \mathrm{~mm})$ pouco presente. 


\subsection{Micromorfologia}

A síntese das descrições microscópicas das amostras em lâminas delgadas para cada horizonte e ilustrada pelas fotomicrografias apresentadas na Figura 6, adiante é apresentada a seguir.

Horizonte A: o fundo matricial é constituído de esqueleto (55\%), plasma (5\%) e poros (40\%). A estrutura de base é composta predominantemente de grãos do esqueleto desprovidos de argila (mônicas) e de poucas zonas com películas descontínuas de argila ao redor do esqueleto (quitônicas) e/ou formando pontes entre eles (gefúricas), (figura 6a). O esqueleto é constituído de quartzo, com predomínio da fração areia fina, pobremente selecionado, subangular, grãos ligeiramente rugosos e distribuição aleatória. O plasma é organo-caulinítico, preto sob luz normal (PPL) e isótico (matéria orgânica) sob luz polarizada (XLP). A porosidade predominante é do tipo intergrãos fina a média (empilhamento simples), fortemente comunicante. Não se constatou feições pedológicas.

Horizonte E: a proporção e a características dos constituintes do fundo matricial é idêntica ao observado no horizonte anterior. O fundo matricial é constituído de grãos do esqueleto desprovidos de argila (mônicas) e secundariamente de microagregados arredondados caulinítico-ferruginosos $(0,5$ a $1 \mathrm{~mm})$ (enáulica) esparsos, poucos.

As bandas onduladas desse horizonte mostraram uma modificação no arranjo do fundo matricial de montante (nascimento) para jusante (dissipação), respectivamente passando de porfírica na sua base, similar ao Btg subjacente, para mônica na sua parte superior e na trajetória para jusante, quando se transforma em horizonte E, marcada por uma transição gefúrica entre ambas tanto vertical como lateralmente (figuras $6 \mathrm{~b}, \mathrm{c}, \mathrm{d}$ ).

Nas bandas suspensas predominam microestruturas gefúricas (pontes) passando progressivamente a mônicasnas transições superiores e inferiores para o horizonte $\mathrm{E}$, sem presença de microagregados e de sinais de hidromorfia.

No volume entre as bandas conectadas e o topo do Btg, as microestruturas são similares àquelas do $\mathrm{E}$, porém se constata a presença de numerosas relíquias do Btg escuras, ligeiramente duras, milimétricas a micrométricas, arredondadas, rugosas, com sinais esparsos de hidromorfia em tons cinza.

Nos volumes interbandas suspensas as características são as mesmas do Horizonte E.

Horizonte Btg: o plasma (30\%) é abundante, tornando o fundo matricial mais denso quando comparado aos horizontes superiores. A organização se faz em blocos milimétricos ( 3 a $5 \mathrm{~mm}$ ) cuja estrutura de base é composta de grãos do esqueleto englobados no plasma cauliníticoferruginoso (porfírica), (figura 6e). O esqueleto (55\%) apresenta predomínio do quartzo, com maior proporção da fração areia fina, é moderadamente selecionado, subangular, com superfície ligeiramente rugosa e distribuído aleatoriamente. A porosidade (15\%) dominante é de poros arredondados à subarredondados do tipo cavitária e de canais. O plasma é heterogêneo, variando do vermelho escuro ao alaranjado (PPL) mostrando-se birrefringente (XLP) nos domínios alaranjados associados às paredes dos poros (vossépica) (figura 6f) e aos grãos do esqueleto (esquelsépica). Ocorrem dois tipos de cutãs cauliníticoferruginosos: associados à porosidade, tipo crescente, com forte birrefringência, microlaminados, com orientação nítida e paralela à parede dos poros, de origem iluvial que representa $10 \%$ do plasma total; e associados aos grãos do esqueleto, com fraca birrefringência e orientação difusa, de transformação por perda de ferro.

Horizonte Bt: as características observadas são semelhantes àquelas do horizonte anterior quanto à estruturade base e componentes, com exceção do plasma, que é homogêneo, vermelho escuro em PPL e isótico em XLP (por opacidade do ferro) e sem presença de revestimentos argilosos, portanto sem evidência de iluviação.

A evolução das microestruturas porfíricas para gefúricas e destas para mônicas (figura 7), bem como o aumento da macroporosidade cavitária desse horizonte indica perda de argila que, no caso, seria principalmente lateral, uma vez que a porosidade abaixo é fina e capaz de bloquear a circulação vertical.

\subsection{Granulometria}

Os resultados gerais da análise granulométrica são apresentados na Tabela 1.

Esses resultados revelam um forte gradiente textural entre os horizontes A, E / Btg, Bt, principalmente nas frações areia fina e argila. Os teores de argila variam de 30-40 a 200$190 \mathrm{gKg}^{-1}$, respectivamente A relação textural B/A indica valores superiores a 6,5 o que caracteriza um contraste textural muito forte, evidentemente com desdobramentos quanto à porosidade, estrutura e comportamento hídrico. As bandasonduladas conectadas apresentaram teores próximos do Btg no pedúnculo e as desconectadas ligeiramente superiores ao E, confirmando resultados intermediários entre os horizontes e a bandas obtidos por Castro (1989a). A relação silte/argila no conjunto dos horizontes B é inferior a 0,7 o que, segundo a Embrapa (1999), indica elevado estágio de intemperismo. 

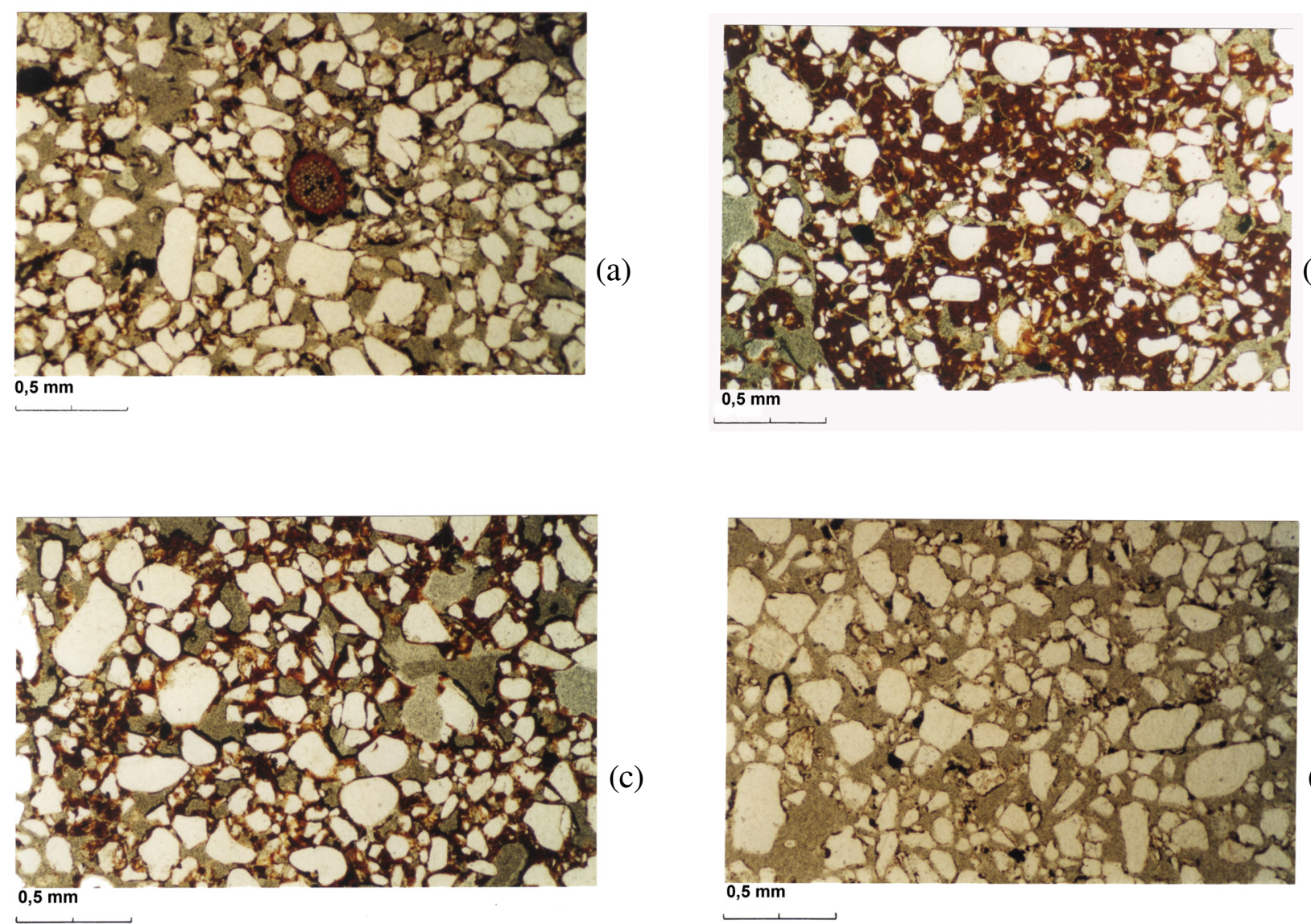

(c)

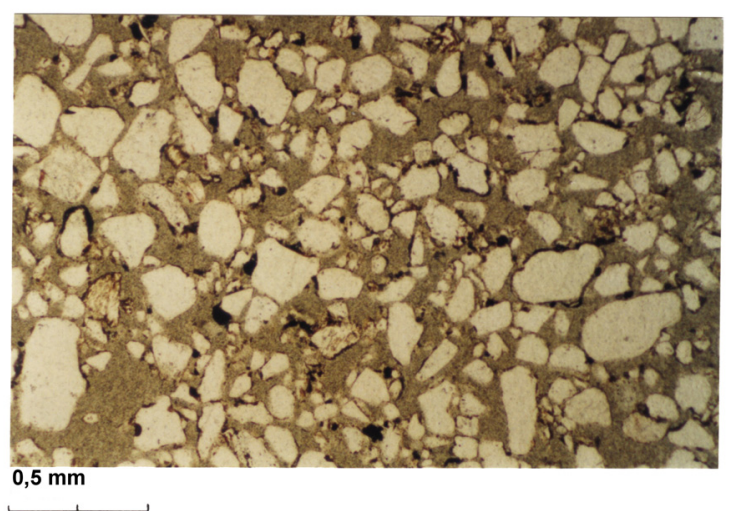

(d)
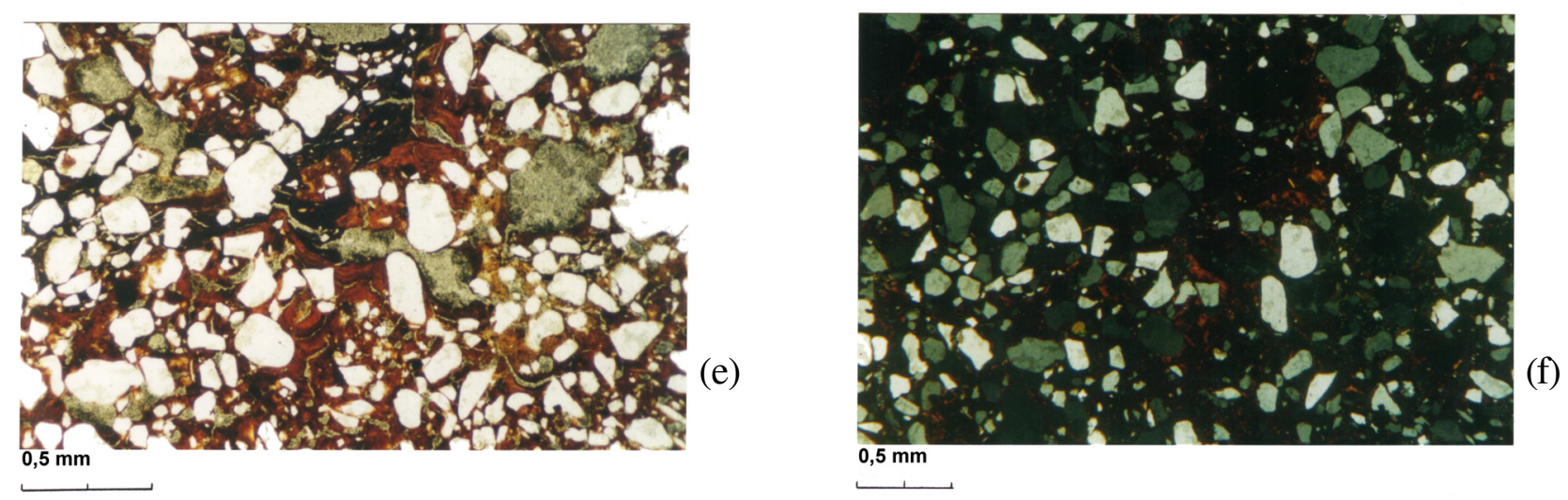

Figura 6 - Fotomicrografias dos horizontes no perfil de solo estudado (Trincheira 4): (a) zonas com películas descontínuas de argila com justaposição de microestruturas do tipo quitônica e gefúrica e zonas desprovidas de argila e microestrutura mônica. Nota-se ao centro da foto restos parcialmente decompostos de vegetais (LPP); (b) domínios porfíricos com plasma vermelho escuro (LPP); (c) domínios gefúricos com plasma vermelho escuro (LPP); (d) domínios mônicos (areia lavada) (LPP); (e) domínios porfíricos com plasma de cor heterogênea, variando do vermelho escuro ao alaranjado (LPP); (f) idem a foto anterior com nicóis cruzados mostrando a existência de plasma birrefringente nos domínios alaranjados associados às paredes dos poros (vossépica) (LPC).

LPP (Luz Polarizada Plana), LPC (Luz Polarizada Cruzada). 


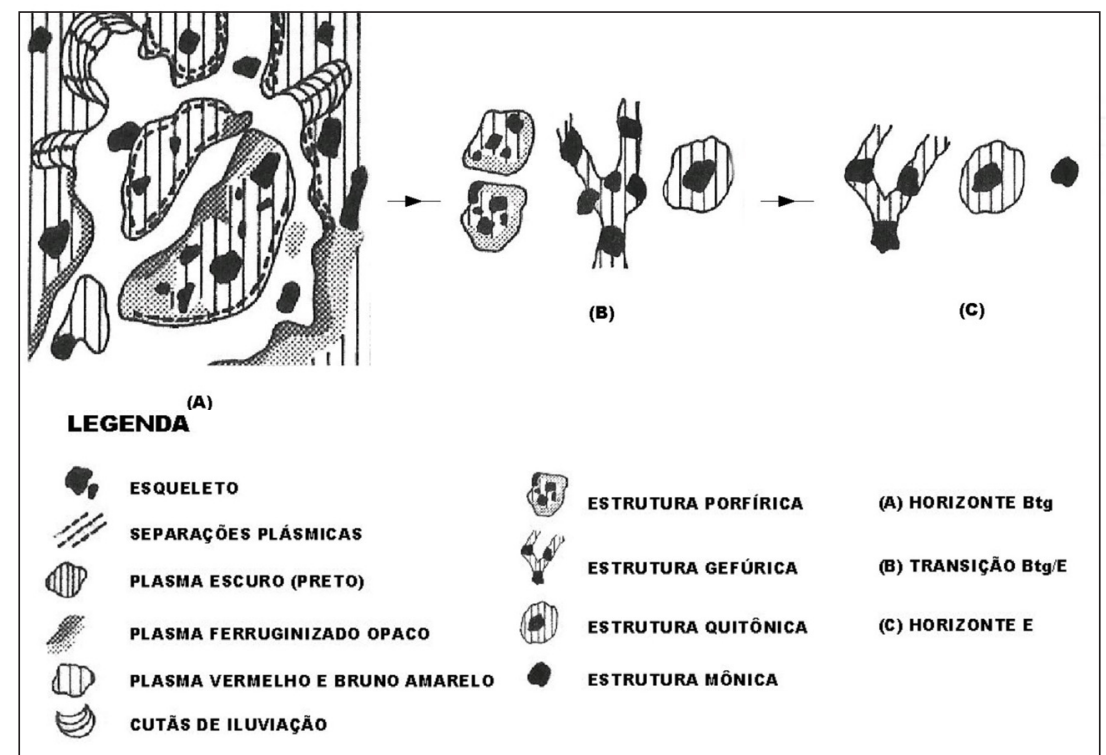

Figura 7 - Modelo interpretativo de evolução das microestruturas

Tabela 1 - Granulometria dos horizontes do Argissolo Vermelho Amarelo da vertente amostral

\begin{tabular}{c|c|c|c|c|c|c}
\hline \multirow{2}{*}{ Horizonte } & \multirow{2}{*}{$\begin{array}{c}\text { Profundidade } \\
\mathrm{cm}\end{array}$} & $\begin{array}{c}\text { Areia } \\
\text { grossa }\end{array}$ & Areia fina & Silte & Argila & Silte/Argila \\
\cline { 3 - 7 } & $0-5$ & 290 & 610 & 60 & 40 & 1.5 \\
\hline $\mathrm{A}$ & $40-45$ & 330 & 580 & 60 & 30 & 2.0 \\
\hline $\mathrm{E}$ & $105-110$ & 300 & 450 & 50 & 200 & 0.25 \\
\hline $\mathrm{Btg}$ & $190-195$ & 250 & 490 & 70 & 190 & 0,37 \\
\hline $\mathrm{Bt}$ & & & & & & $\mathrm{Kg}^{-1}$ \\
\hline
\end{tabular}

\subsection{O comportamento físico-hídrico}

Os resultados das medidas físico-hídricas são apresentados na Tabela 2.

Nota-se que os horizontes A e E, com condutividade hidráulica elevada $(71 \mathrm{~mm} / \mathrm{h})$, apresentam quantidade expressiva de macroporos (13 e 15\%), embora os microporos sejam significativos (22-18\%) e a porosidade total não seja significativa (35-33\%), enquanto que nos horizontes Btg e $\mathrm{Bt}$, com condutividade hidráulica baixa $(4$ e $6 \mathrm{~mm} / \mathrm{h}$ ), predominam os microporos (31 e $27 \%$ ) com poucos macroporos (6 e 9\%), embora a porosidade total seja até ligeiramente superior (37-36\%) àquela dos horizontes Ae E. Isto confirma a interpretação dada por Salomão $(1994,1999)$ quando este afirma que a porosidade total pode ser a mesma ou próxima entre tais horizontes, mas o que controla a circulação dos fluxos é a macroporosidade, portanto, é importante analisar a distribuição entre macro e microporos e não apenas a porosidade total. No caso, a macroporosidade reduzida do Btg e Bt dificulta a percolação, dando-se o oposto nos horizontes A e E.

Tabela 2 - Parâmetros físico-hídricos dos horizontes do Argissolo Vermelho

\begin{tabular}{c|c|c|c|c|c}
\hline & & Porosidade & \multicolumn{2}{|c}{$\begin{array}{c}\text { Distribuição dos } \\
\text { Poros }(\%)\end{array}$} & \multirow{2}{*}{ Horizonte } \\
\cline { 4 - 5 } & Profundidade & Total $(\%)$ & $<30 \mu \mathrm{m}$ & $>30 \mu \mathrm{m}$ & $\begin{array}{c}\text { Ksat* } \\
\text { (mm.h-1) }\end{array}$ \\
\hline $\mathrm{cm}$ & $0-5$ & 35 & 22 & 13 & 71 \\
\hline $\mathrm{E}$ & $40-45$ & 33 & 18 & 15 & 71 \\
\hline $\mathrm{Btg}$ & $105-110$ & 37 & 31 & 6 & 6 \\
\hline $\mathrm{Bt}$ & $190-195$ & 36 & 27 & 9 & 4 \\
\hline
\end{tabular}

* Condutividade hidráulica saturada 
Além disso, a micromorfologia revelou que nos horizontes A e E a porosidade é predominantemente intergrãos (mônicas) e fortemente comunicante, embora microestruturas gefúricas e quitônicas, tanto ligadas ao plasma mineral como orgânico, possam se relacionar com a microporosidade. Já nos horizontes Btg e Bt, com microestruturas porfíricas, predominam os poros arredondados a subarredondados e canais alongados, todos fracamente comunicantes.

Tais resultados evidenciam descontinuidade textural e, sobretudo estrutural no conjunto do perfil, similar ao demonstrado por Santos et al (1998). O maior percentual de argila e o predomínio de uma estrutura mais adensada, com poros arredondados a subarredondados, fracamente comunicantes no conjunto dos horizontes Bt e Btg, além de reduzirem sua capacidade de percolação, aumentando a reserva total de água, favorecem a instalação de lençol suspenso no Btg, que, dado o declive, desenvolve fluxos laterais. Convém lembrar que as bandas promovem também pequenos fluxos laterais acima delas, como constatado por Queiroz Neto et al. (1995) para solos similares e Salomão (1994) para os mesmos solos do presente estudo.

Os fluxos hídricos seriam responsáveis pela remoção das argilas dispersas do horizonte $\mathrm{E}$, as quais migrariam para o topo do Bt preenchendo a macroporosidade na forma de cutãs de iluviação, o que dificultaria a drenagem e potencializaria a hidromorfia suspensa, a qual afetaria também o plasma não iluvial criando cavidades de dissolução, além de microlaminações e zonações pós-deposicionais nos cutãs iluviais, transformando-o em Btg. Por outro lado, tais condições são redutoras , portanto capazes de dissociar FeArgila e sua subseqüente migração, separadamente, via lençol suspenso.

\section{Discussão}

A segregação pós-deposicional dos revestimentos argilosos relacionados à hidromorfia pode apresentar maior resistência que a do plasma do entorno, o que explicaria sua permanência na base das bandas servindo-lhes de sustentação, ao mesmo tempo em que bloqueariam a circulação posterior favorecendo, assim, nova iluviação. Mas, à medida que a eluviação das argilas acima progride, essas microestruturas também se desestabilizam, cujos fragmentos restam residuais nos bolsões arenosos do topo do Btg abaixo dos pedúnculos. Portanto, no conjunto o processo é e-iluvial, onde a eluviação é o motor e a iluviação um mecanismo coadjuvante e temporário, que não recupera a perda da argila e do ferro, coincidindo com o observado por Castro (1989a, 1996), Cunha \& Castro (1996), Vidal -Torrado et al. (1999), Santos (1995, 2004) e Santos et al (1998).
Esses mecanismos e-iluviais teriam uma duração temporária, visto que a drenagem lateral, cada vez mais potente, poderia causar poro-pressões suficientes para desestruturar as microestruturas e abrir zonas de passagem para baixo e também lateralmente no rumo jusante (Santos et al, 1998), sendo responsáveis pela conformação em semiarco das bandas, até que estas também se degradem e se dissipem completamente, desaparecendo no seio do horizonte eluvial $\mathrm{E}$, à medida que o topo do Btg se degrada $\mathrm{e}$ sofre perda de matéria, causando progressivo espessamento do horizonte E (Castro, 1989a). Por outro lado, a presença de hidromorfia mais espessa abaixo do pedúnculo das bandas indica ser esse ponto de maior volume de saturação.

Tal processo ganha, assim, energia para jusante, favorecida pelo declive e o desnível topográfico, que se acentua progressivamente com esses mecanismos, o que impediria a formação de bandas e de Bt ou mesmo Btg nessa posição, dada a remoção rápida e eficaz de finos. Feições reliquiais entre as bandas e o Btg, bem como o desaparecimento das bandas rumo à superfície dos perfis e para jusante, atestam que o processo se aprofunda, rebaixando ligeiramente a vertente, ao mesmo tempo em que o horizonte E se espessa pra jusante e remonta cada vez mais a vertente, num processo de reequilíbrio.

Em termos geomorfológicos, a partir das rupturas de declive côncavas entre o topo e terço superior, esse processo marca espacial e funcionalmente o aparecimento dos mecanismos de perda superficial de finos, de transformação do Bw em Bt e o aparecimento das bandas conectadas como feições residuais. Assim, paralelamente às perdas e à abertura da porosidade, o aumento de energia da drenagem interna lateral acima do Btg o que promoveria a instalação de fluxos superficiais erosivos pelo escoamento concentrado das águas pluviais, conduzindo à remoção continuada de matéria que aumentaria progressivamente o rebaixamento altimétrico nessa posição da vertente.

Ao longo do ano hidrológico sob sazonalidade climática do tipo tropical, há variação das taxas de infiltração, percolação profunda, deflúvio superficial, fluxos subsuperficiais saturados e não saturados e piping que freqüentemente variam nas vertentes. Assim, a vazão superficial e subsuperficial aumentando progressivamente, sem prejuízo de oscilações, conduziriam a reajustes hidráulicos e à conformação das vertentes dos interflúvios como um todo, o que, por sua vez, também seria responsável por rápida saturação basal da vertente e subsequentemente à gleização. No entanto, esse aumento não seria regular ao longo das estações do ano e entre anos sucessivos, mas chuvas intensas e em dias consecutivos, diante de saturação sub-superficial ou de excedente em relação à taxa de infiltração podem promover ascensões rápidas do nível de base 
induzindo ascensão do lençol na vertente, e intensificação dos fluxos superficiais, capazes de promover a dissecação erosiva hídrica superficial descendente e a remoção interna de finos, remontantemente.

$\mathrm{Na}$ estação seca esses fluxos e níveis e espessuras de faixas de saturação rebaixariam naturalmente, promovendo apenas escoamento sub-superficial com vazão reduzida, embora com competência para a remoção de finos, ainda que reduzida. Por outro lado, o aumento do gradiente hidráulico, dado o rebaixamento da vertente e do nível de base local, seria capaz de potencializar ainda mais a energia dos fluxos subsuperficiais, gerando formação de tubulações (piping) no contato $\mathrm{E} / \mathrm{Btg}$, também promotores de subsidências na topografia externa da vertente, concentradoras de novos fluxos superficiais lineares (Salomão, 1994).

A existência dos pedúnculos e sua dissipação completa para jusante, o pouco contraste do horizonte $\mathrm{E}$ a montante quando as bandas surgem conectadas, onde praticamente não há bandas desconectadas, os "empilhamentos" de numerosas bandas conectadas e desconectadas no trecho médio do segmento corroboram a interpretação de autodesenvolvimento remontante como resposta à alternância climática sazonal. A concentração notável de bandas onduladas no segmento médio da vertente testemunha a retirada lenta e sazonal de matéria para jusante e a interpretação de que a pedogênese e-iluvial e a maior atividade morfogenética se situam exatamente nesse trecho, porém não são suficientemente enérgicas para destruir as bandas onduladas por completo.

Em adição, a instalação de convergência de fluxos superficiais capazes de promover a erosão hídrica por escoamento concentrado, contribuiria para seu rebaixamento erosivo. $\mathrm{O}$ aporte de areia à jusante, por coluvionamentos sucessivos, movimentos de massa (rastejo), piping na transição E-Btg e até mesmo mistura alúvio-coluvial na base da vertente, capaz de promover o enterramento dos antigos horizontes A húmicos ou mesmo hísticos, como visto na base da toposseqüência, apontam na direção de que o córrego não teria competência suficiente para evacuação dos materiais retirados das posições a montante, e por outro lado fortalecem a interpretação de uma evolução solo - relevo solidária, como defendido por Queiroz Neto (2000).

Resta saber, no entanto, como começou esse processo e relacionado à que fenômeno. $\mathrm{O}$ aprofundamento dos talvegues relacionado a mudanças de nível de base póscretácicos, atribuídos a ambientes tropicais cada vez mais úmidos, poderia ser responsável pelo desencadeamento de re-esculturação dos interflúvios pré-existentes e ao desequilíbrio da cobertura latossólica inicial condicionados pelos subseqüentes reajustes hidráulicos e sucessivos das vertentes e sua gradativa transformação pedogenética em superfície e sub-superfície formando Bt, depois Btg e E com bandas para, por fim, sem bandas. Reforça essa interpretação o fato de que a conformação das bandas onduladas, bem como dos horizontes da cobertura argissólica e latossólica subjacente ao Bt são concordantes com a forma atual das vertentes e não há indícios de truncamento erosivos das superfícies, o que revela a penecontemporaneidade do fenômeno, sem significativas oscilações climáticas.

O Argissolo seria então posterior à cobertura inicial latossólica, do qual guarda resíduos na sua base, e evolui por e-iluviação acima do $\mathrm{Bt}$, confirmado pelas transições e feições residuais, onde aparecem padrões mistos transicionais ou justapostos - onde se encontram os indicadores dos processos (Bullock et al., 1985; Castro 1989a e 1999). A hierarquia e a cronologia relativa entre os padrões ora encontrados e sucessivos padrões intermediários convergem com essa mesma interpretação e se tornaram importantes para interpretar a chave e o sentido provável da sua origem e evolução sucessiva, concordando com Castro et al. (2003), como a seguir:

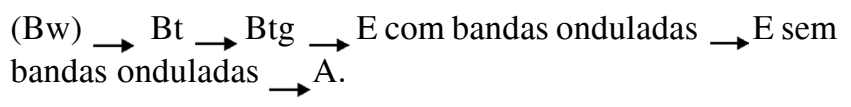

Em síntese, considera-se evidências do processo: a) a evolução das microestruturas cimentada (porfírica) do Bt e do Btg para pontes de argila (gefúrica) no topo deste último que evolui para grãos envolvidos por películas (quitônica) no contato E/Btg e esta para grãos lavados (mônica) no horizonte E, revelando desestabilização estrutural do Bt e sua degradação no topo por hidromorfia (Btg e bandas conectadas);

b) a presença de relíquias do Btg entre as bandas e o topo desse horizonte, progressivamente menores e mais esparsas nos volumes interbandas, testemunhando sua presença em posições anteriormente mais altas nos perfis;

c) a conformação em semi-arco das bandas projetado para jusante e a dissipação terminal das mesmas cujas estruturas assemelham-se às das bandas desconectadas, testemunhando filiação genética entre elas e o Btg;

d) a ausência de hidromorfia no Bt bem como de feições de iluviação atestam que o fenômeno e-iluvial afeta diretamente a parte superior do solo em concordância com a dinâmica hidropedológica do relevo atual, no caso a partir da ruptura côncava situada no limite entre o terço superior para o médio; e) o espessamento do horizonte E para jusante, se evidências de estratificações, revelando a energia do processo eluvialnessa posição. 
Como há bandas conectadas e desconectadas numa mesma posição, o fenômeno parece evoluir por ciclos, embora de maneira lenta e gradual, como na forma de pulsos, o quecorroboraria a idéia de relação com sazonalidade climática.Assim, a vertente seria resultante de mecanismos geomorfológicos e pedogenéticos inter-relacionados e complexos: a formação do Bt subjacente por possível adensamento do $\mathrm{Bw}$; a potente perda de matéria para jusante, sobretudo argila, nos horizontes superficiais e subsuperficiais do Argissolo; a erosão hídrica superficial e sub-superficial. Portanto, o sistema Latossolo-Argissolo, em particular de seus horizontes $\mathrm{Bt}$, Btg e E com ou sem bandas, sugere evolução morfopedológica, isto é solidária, onde o rebaixamento progressivo da topografia favorece sua dissecação e potencializa ainda mais o rebaixamento topográfico, o que demandaria um novo reajuste hidráulico da vertente e assim sucessivamente. Não há, portanto, evidências de perdas como nas formas de subsidência originada de subtração geoquímica em profundidade, associada aos sistemas de fraturas subverticais, comuns em áreas cristalinas, ou dissolução no contato solo/rocha, mais comuns em áreas sedimentares ricas em carbonato de cálcio ou magnésio.

Resta saber a origem do desequilíbrio hidráulico dos interflúvios iniciais e da sua cobertura latossólica inicial, se a umidificação do clima quaternário responsável teria promovido o aprofundamento dos talvegues e demandado o reajuste hidráulico e progressivamente morfopedogenético ou se fenômenos de origem (neo) tectônica de subsidência regional ou ainda outro de origem paleoclimática. De qualquer modo, certamente não foi um rebaixamento rápido, caso contrário não daria tempo para o desenvolvimento das feições lamelares relatadas e sua concordância com a vertente atual tampouco seria tão evidente.

Nesse sentido, há que se ressaltar que tais processos parecem ativos, posto que as bandas não foram completamente destruídas, mas não se sabe quanto tempo é necessário para sua formação, tampouco para sua degradação. Todavia, em se tratando de meio percolante, é de supor que necessitariam de condições subúmidas ou úmidas para se desenvolverem, o que reforça a idéia da tropicalidade do clima.

Considerando-se o razoável consenso entre os quaternaristas de que no sudeste do país os paleoclimas já eram subúmidos tendendo ao úmido, similares ao atual, desde cerca de 7 mil anos AP, apesar de pequenas oscilações e da carência de datações (Suguio, 2001; Coltrinari, 1992), os fenômenos geomorfológicos e pedogenéticos interrelacionados e aqui relatados se associariam muito provavelmente à essa condição climática úmida.

\section{Conclusões}

- As características morfológicas, micromorfológicas e físico-hídricas do Argissolo são congruentes entre si e apontam para mecanismos de perdas e reorganização textural e, sobretudo estrutural, ligadas à e-iluviação.

- O desenvolvimento das colinas médias é interrelacionado com a transformação pedológica vertical e lateral em resposta a reajustes hidráulicos dos interflúvios, fenômeno comum em bordas de platô dissecado.

- Essas modificações são induzidas por fluxos hídricos que geram hidromorfia no topo do horizonte Bt originando um Btg e a instalação de lençol suspenso responsável pelo desencadeamento de processo e-iluvial descendente marcado por estruturas de acumulação dupla temporárias (bandas onduladas e relíquias do Btg) e por acumulações residuais remontantes de areia (horizonte $\mathrm{E}$ ).

- As bandas onduladas seriam testemunhas residuais, embora temporárias, de que o horizonte $\mathrm{Bt}$ e consequentemente seu subhorizonte Btg, já estiveram mais elevados nos perfis antes de sua eluviação, o que poderia se dar em ciclos.

- O rebaixamento do terço médio da vertente poderia resultar também, de erosão hídrica superficial e subsuperficial, mas haveria um indutor hidrológico inicial (rebaixamento hidráulico do nível de base) e um pedológico relacionado (sistema pedológico de transformação lateral) para explicar o processo morfopedológico, ainda insuficientemente esclarecido, entretanto ainda funcional.

- É possível que esses fenômenos tenham se iniciado com a instalação das condições subúmidas tendendo ao úmido reinantes na região sudeste do país, desde pelo menos o início do Holoceno, sendo as colinas médias da borda de platô a consequiência desses fenômenos, integrados numa lógica geomorfopedológica complexa, porém continuada, isto é sem truncamentos erosivos, assim, se o platô é Póscretáceo, esse processo pode ser correlativo e ter continuado por auto-desenvolvimento.

- A filiação genético-evolutiva entre Bt, Btg, bandas onduladas e E no desenvolvimento do terço médio da vertente seria, assim, singenética, ou solidária, que conduz tanto ao desenvolvimento do sistema pedológico de transformação lateral como ao rebaixamento hidráulico da vertente, correlativamente. 


\section{Referências Bibliográficas}

Ab'Saber, A.N. (1969a) Um conceito de Geomorfologia a serviço das pesquisas sobre o Quaternário. São Paulo, Geomorfologia, 18. Instituto de Geografia.São Paulo: USP, 23p.

Ab’Saber, A.N. (1969b) A Depressão Periférica Paulista: um setor de circundesnudação pós-cretácica na Bacia do Paraná. Universidade de São Paulo, Instituto de Geografia, São Paulo. Geomorfologia, 15, 15p.

Ab’Saber, A.N. (1969c) Uma revisão do Quaternário Paulista do presente para o passado. Rev.Bras. de Geografia, 31 (4):1-33.

Almeida, F.F.M de. (1964) Fundamentos geológicos do relevo paulista. São Paulo: IGG, 41, p. 167-263. (separata).

Beltrame, A.V.; Boulet, R.; Castro, S.S.; Pellerin, J.; Queiroz Neto, J.P. \& Scheibe, L F. (1991) Depressions fermeés et sols developpés sur migmatites du Plateau Atlantique Sud-Brésilien (Etat de Santa Catarina). In: Table ronde Organisation et Dynamique Interne de la Couverture Pedologique et Son Importance Pour la Comprehension de la Morphogenese, Anais: 21.

Bigarella, J (1975) Structures deveoped by teh dissipation of dune and beach ridge deposits. Catena, 1: 107152.

Bigarella, J. \& Mousinho, M.R. (1965a) Considerações a respeito dos terraços fluviais, rampas de colúvio e várzeas. Curitiba, Bol. Paranaense de Geografia 16e 17: 153-197.

Bigarella, J. \& Mousinho, M.R. (1965b) Considerações a respeito da evolução das vertentes. Curitiba, Bol. Paran. de Geografia, 16e 17:117-151.

Bocquier, G. (1973) Génèse et évolution de deux toposéquences de sols tropicaux du Tchad: interprétation biogeodynamique. Mémoires ORSTOM, 62.

Bond, W.J. (1984). Illuvial band formation in a laboratory column of sand. Soil Sc. Soc. American Journal, 50: 309-328.

Boulet, R. (1992) Uma evolução recente da Pedologia e suas implicações no conhecimento da gênese do relevo In: Anais do III Congresso ABEQUA. Belo Horizonte, p.43-58.

Boulet, R. (1988) Análise estrutural da cobertura pedológica e cartografia. XXV Congr. Bras. de Ciência do Solo. Anais. Campinas, p. 79-90.

Boulet, R.; Chauvel, A.; Humbel, F.X. \& Lucas, Y. (1982a) Analyse structurale et pédologie I. Prise em compte de l'organisation bidimensionnelle de lacouverture pédologique: les études de toposéquences et leurs principaux apports à la connaissance des sols. Cah. ORSTOM, sér. Pédol., vol.XIX, nº 4: 309322.

Boulet, R.; Humbel, F.X. \& Lucas, Y. (1982b) Analyse structurale et cartographie en pedologie II. Une méthode d'analyse prenant en compte l'órganisation tridimensionnelle des couvertures pédologiques. Cah. ORSTOM, sér. Pédol., vol XIX, n4:323-339.

Boulet, R.; Chauvel, A . \& Lucas, Y. (1984) Les systèmes de transformation en pédologie. In Livre Jubilaire du cinquantenaire de l'AFES, Paris: 167-179.

Brewer, R. (1976) Fabric and mineral analysis of soils - Krieger R. E. Ed. New York, 482p.

Bullock, P.; Fedoroff, N.; Jongerius, A.; Stoops, G. \& Tursina, T. (1985) Handbook for soil thin section description. Waine Research Publs, 152p.

Bullock, P. \& Thompson, M.C. (1985) Micromorphology of Alfissol. In Douglas, L. (ed.) Soil Micromorphology. Madison, Soil Sci. Soc. of America, Special Issue, 15: 17-47.

Buol, S.W. (1983) Pathways of Oxisol formation. In: International Soil Classification Workshop, 4. Ruanda. Proceedings. Bruxelas, p.377-395.

Carvalho, A. (1976) Solos da Região de Marília (SP):relações entre a pedog^ ${ }^{\wedge}$ Çenese e a evolução do relevo. São Paulo, Universidade de São Paulo, 163 p. (Tese de Doutorado)..

Castro, S.S. (1985) Impregnação de amostras de solo para confecção de lâmina delgada. In: Boletim Informativo. Campinas: SBCS, $n^{\circ}$ 31, p.44.

Castro, S.S. (1989a) Sistema de Transformação Pedológica em Marília, SP: B latossólico e B textural. São Paulo (Tese de Doutorado-Geografia /USP), 274p.

Castro, S.S. (1989b) Micromorfologia de solos: pequeno guia para confecção de lâminas delgadas. Apostila (mimeografada)-apoio IPT, CAPESXCOFECUB e DG-USP. São Paulo, 87p.

Castro. S.S. (1996) Micromorfologia de Domínios Orientados em Latossolo Vermelho Escuro e Podzólico Vermelho Amarelo filiados. Res. Exp. CDROOM Anais XIII Congresso Latino Americano de Ciência do Solo, Águas de Lyndóia, SP, Brasil.

Castro, S.S. (1999) Micromorfologia de solos aplicada ao diagnóstico de erosão. Cap.4 in Erosão e Conservação de Solos: conceitos, temas e aplicações de GUERRA et al. (org.). Rio de Janeiro, 
Bertrand Brasil:. 127-163.

Castro, S.S. \& Coelho Netto, A.L. (2002) Evolução pedogenética em depressão de topo na bacia do alto rio Fortaleza, região do Bananal (RJ): resultados preliminares. In: IV Encontro Sobre Engenharia Geotécnica e Hidrologia no Sistema Encosta-Planíce Costeira. PRONEX/FINEP. Rio de Janeiro, Anais 181-192.

Castro, S.S.; Cooper.; Vidal-Torrado, P. \& Carneiro, M. (2003) Micromorfologia de solos: bases e aplicações. Viçosa: Tópicos em Ciência do Solo, 3: 107-164.

Castro, S.S. \& Curmi, P. (1987) Bandas onduladas em solos podzolizados variação Marilia: estruturas de transformação pedológica. Congresso Bras. de Ciência do Solo, SBCS, XXV, Campinas, Anais: Resumo: 34-36.

Castro, S.S.; Hallaire, V. \& Curmi, P. (1993) Macroporosidade de um solo Podzólico Vermelho Amarelo de Marília, SP, através de analisador de imagens. Res. e painel, XXIV Congresso Bras. de Ciência do Sol, Goiânia: vol. 1: 113- 115.

Chauvel, A. (1977) Recherches sur la transformation des sols ferrellitiques dans la zone tropicale a saisons contrastées. ORSTOM, Paris, série Travaux et Documents, 62, $532 \mathrm{p}$.

Coelho Netto, A.L. (2004) Evolução de cabeceiras de drenagem no médio vale do rio Paraíba do Sul (SP/ $\mathrm{RJ})$ : bases para um modelo de formação e crescimento da rede de canais sob controle estrutural. Goiânia: Rev. Bras. de Geomorfologia, 4, 2: 118-167.

Coltrinari, L. (1992) Paleoambientes quaternários na América do Sul: primeira aproximação. In: Anais do III Congresso ABEQUA. Belo Horizonte, p.13-42.

Comissão de Solos (1960) Levantamento de reconhecimento dos solos do Estado de São Paulo. Rio de Janeiro, Ministério da Agricultura, CNEPA, SNPA, 634p. (Boletim 12).

Cooper, M.; Vidal-Torrado, P. \& Lepsch, I.F. (2002) Stratigraphical discontinuities, tropical landscape evolution and soil distribution relationships in a case study in SE-Brazil. Revista Brasileira de Ciência do Solo. Viçosa: v. 36, n. 3, p. 673-683.

Cunha, J.E. (1996) Caracterização morfológica (macro e micro) e comportamento físico-hídrico de duas topossequiências em Umuarama (PR): Subsídios para avaliação dos processos erosivos. São Paulo (Dissertação de Mestrado-Geografia/USP), 129p.

Cunha, J.E. \& Castro, S.S. (1996) Características físicohídricas e micromorfológicas da toposseqüência Córrego Longe em Umuarama, PR. in XIII Congr. Latino - Americano de Ciência do Solo Anais CDROM 05 -058, Águas de Lyndóia.
Cunha, J. E.; Castro. S.S. \& Salomão, F.X. T (1999) Comportamento erosivo de um sistema pedológico em Umuarama, Noroeste do Paraná. Rev. Bras. de Ciência do Solo 23(4): 943-952, Viçosa.

Dijkerman, J.C.; Cline, M.G. \& Olson, G.W. (1967) Properties and genesis of textural subsoil lamellae. Soil Sci., 104: 7-16.

Embrapa (1999) Sistema Brasileiro de Classificação de Solos Brasília: Embrapa Produção de Informação; Rio de Janeiro: Embrapa Solos, 412p.

Fernandes, A.F. \& Coimbra, A.M. (2000) Revisão Estratigráfica da parte oriental da Bacia Bauru (Neocretáceo). Revista Brasileira de Geociências. São Paulo: v.30, n.4: 717-728.

Fernandes Barros, O.N. (1985) Análise estrutural e cartográfica detalhada de solos em Marília, Estado de São Paulo: ensaio metodológico. São Paulo (Dissertação de Mestrado. Geografia Física/USP), 146p.

Fernandes Barros, O.N.; Queiroz Neto, J.P. \& Pellerin, J. (1991) Analyse structurale et comportement hydrique de la couverture pedologique du plateau de MaríliaSP-Brésil. In: Table Ronde Organisation et Dynamique Interne de la Couverture Pedologique et Son Importance Pour la Comprehension de la Morphogenese.

Filizola, H. \& Boulet, R. (1996) Evolution and opening of closed depression developed in a quartz-kaolinic sedimentary substratum at Taubaté basin (São Paulo, Brazil) and analogy to the slope evolution. Geomorphology, 16, 77-86.

Fitzpatrick, E.A. (1980) The micromorphology of Soils. Dept. of Soil Science, University of Aberdeen, Scotland, 186p.

Furquim, S.A.C. (2002) Interação entre modelado e solo no transecto Espraiado, São Pedro. São Paulo (Dissertação de Mestrado-Geografia/USP), 183p.

Hallaire, V.; Castro, S.S. \& Curmi, P. (1994) Image analysis of main horizons of an Oxisol/Ultisol toposequence in São Paulo State (Marília, SP, Brazil) In $15^{\text {th }}$ World Cong. of Soil Science, Acapulco, México, Abstract: 94-95.

IPT (1981) Mapa Geomorfológico do Estado de São Pauloescala 1:1.000.000 (com memorial), São Paulo, SP, Vol.II.

Jacomini,P.K.T. (2005) Origem e evolução dos conceitos e definições de atributos, horizontes diagnósticos e das classes de solos do Sistema Brasileiro de Classificação de Solos (SiBCS). Tópicos Ci. Solo, 4: 193-231.

Klute, A. (1986) Methods of soil analysis. Part 1: Physical and Mineralogical Methods. Madison, Wisconsin USA. ASA/SSSA, 188p. 
Köeppen, W. (1948) Climatologia. Con un estudio de los climas de la tierra. México, FCE.

Lemos, R. C. \& Santos, R. D. (1984) Manual de descrição e coleta do solo no campo. Sociedade Brasileira de Ciência do Solo. SNLCS, $2^{a}$ edição, Campinas-SP, $46 \mathrm{p}$.

Lepsch, I.F.; Buol, S.W. \& Daniels, R.B. (1977a) Soil landscape relationships in the occidental plateau of São Paulo, Brazil: I geomorphic surfaces and soil mapping units. Soil Sci. Soc. Am. J., Madison, 41:104-109.

Lepsch, I.F.; Buol, S.W. \& Daniels, R.B. (1977b) Soil landscape relationships in the occidental plateau of São Paulo, Brazil: II Soil morphology, genesis and classification. Soil Sci. Soc. Am. J., Madison, 41:109-115.

Libardi, P.L. (1984) Dinâmica da água no sistema solo-plantaatmosfera. Piracicaba, Cena/Esalq/USP. 232p.

Lucas, Y.; Chauvel, A.; Boulet, R.; Ranzani, G. \& Scatolini, F. (1984) Transição latossolos-podzóis sobre a formação Barreiras na região de Manaus, Amazônia. R. Bras. Ci. Solo. Campinas, 8:325-335.

Manfredini, S., Queiroz Neto, J. P. (1993). Comportamento hídrico de sistema de transformação lateral B latossólico, B textural em Marília (SP). In: Congresso Brasileiro de Ciência do Solo, 24, 1993, Goiânia. Anais... Goiânia: SBCS. V. 1, p. 91-93.

Moniz, A.C. \& Buol, S.W. (1982) Formation of an OxisolUltisol transition in São Paulo, Brazil: I Doublemater flow model of soil development. Soil Sci .Soc. Am. J.; Madison, 46: 1228-1233.

Moniz, A.C. (1992) Evolução dos conceitos no estudo de gênese de solos. Rev.Bras. Ci. Solo, 20: 349-302.

Oliveira, D. (1997) Estudo macro e micromorfológico de uma topossequiência na bacia do Córrego do Retiro em São Pedro-SP (Dissertação de MestradoGeografia/USP), 142p.

Oliveira, D.; Castro, S.S. \& Ferreira, R.P.D. (1998) Indicadores macro e micromorfológicos da circulação hídrica dos solos de uma topossequiência em São Pedro (SP). Florianópolis: Geosul 14 (27): 482-487.

Paisani, J.C. (2001) Estrutura de Dissipação: uma revisão conceitual. In Pesquisas em Geociências, Porto Alegre, UFRGS, 28(2):133-140.

Paisani, J.C. (2004 a) Gênese de Lamelas ("estruturas de dissipação") Associadas à Evolução de Paleoargissolos em Rampa Arenosa, Praia Mole (Ilha de Santa Catarina)/SC, Brasil: subsídios para uma interpretação paleogeomorfológica. Goiânia,
Revista Brasileira de Geomorfologia Vol 5, nº 1:2942.

Paisani, J.C. (2004 b) Estratigrafia. Significado paeloambiental e evolução de rampa arenosa/dissipação no Balmeário Praia Mole, Ilha de Santa Catarina. Tese de Doutorado em Geografia, UFSC, 255p.

Pellerin, J. \& Queiroz Neto, J.P. (1992a) Relations entre la distribuition des sols, les formes et l'évolution géomorphologique du relief dans la haute vallée du Rio do Peixe (Etat de São Paulo, Brésil). Science du Sol, vol.30, n³: 133-147.

Pellerin, J. \& Queiroz Neto, J.P. (1992b) Morfogênese e pedogênese no Córrego da Invernada (Marília, SP) In: Anais do III Congr. da ABEQUA. Belo Horizonte, p.111-122.

Penteado, M.M. \& Ranzani, G. (1973) Problemas geomorfológicos relacionados com a gênese dos solos podzolizados, Marília, SP. Inst. de Geografia/ USP, Sér. Sedimentologia e Pedologia, 6, 23p. São Paulo.

Queiroz Neto, J.P. (1975) Observações preliminares sobre perfis de solos com bandas onduladas do Estado de São Paulo, Inst. de Geografia/USP, Sér. Sedimentologia e Pedologia, 7, 34p. São Paulo.

Queiroz Neto, J.P. (2000) Pedologia e Geomorfologia. Campinas: Revista Brasileira de Geomorfologia, Ano 1(1): 59-67.

Queiroz Neto, J.P.; Carvalho, A.; Journaux, A. \& Pellerin, J. (1973) Cronologia dos solos da região de Marília, São Paulo, IGEOG-USP, Sedimentologia e Pedologia, 5: 55p.

Queiroz Neto, J.P.; Castro, S.S.; Fernandes Barros, O.N.; Manfredini, S.; Pellerin, J.; Ruellan, A. \& Toledo, G.S. (1981) Um estudo de dinâmica de solos: formação e transformação de perfis com horizonte B textural. Anais do XVII Congresso Brasileiro de Ciências do Solo, SBCS, Salvador (BA).

Queiroz Neto, J.P., Fernandes Barros, O.N. \& Manfredini, S. (1995) Comportamento hídrico dos solos e erosão no Plateau de Marília (SP) Bauru: Simp. Nac. de Controle de Erosão, 5, Anais:169-173.

Queiroz Neto, J.P.\& Journaux, A. (1978) Carta geomorfológica do Vale do rio do Peixe em Marília, SP. São Paulo, IGEOG/USP, Série Sedimentologia e Pedologia, 10, 23p.

Rawling, J.E., 3rd (2000) A review of lamellae. Geomorphology, 35:1-9.

Rueda, J.J. (1985) Pedogênese da Formação Marília (grupo Bauru) da região de Monte Alto, SP. Tese de 
Doutorado, Escola Superior de Agricultura Luiz de Queiroz, Piracicaba, 210p.

Rueda, J. R.J. \& Demattê, J.L.I (1988) Solos originados de lamitos da Formação Marília (Grupo Bauru) da região de Monte Alto. Rev.Bras. Ci. do Solo, 12 92):161-170.

Ruellan, A. \& Dosso, M. (1993) Regards sur le sol. Les Editions Foucher, Paris, 192 p.

Rolim, Neto. F.C. \& Santos, M.C.D. (1994) Gênese de solos arenosos com lamelas no agreste de Pernambuco. R. Bras. Ci. Solo, Campinas 18: 243-253.

Salomão, F.X.T. (1994) Processos Erosivos Lineares em Bauru, SP: regionalização cartográfica aplicada ao controle preventivo urbano e rural. São Paulo (Tese de Doutorado-Geografia/USP), 200p.

Salomão, F.X.T. (1999) Controle e Prevenção dos Processos Erosivos. In: Guerra, A. J. T.; Silva, A. S.; Botelho, R. G. M. (Org.) Erosão e Conservação dos Solos: conceitos, temas e aplicações. Rio de Janeiro, Bertrand Brasil, $340 \mathrm{p}$.

Santos, L.J.C.; Castro, S.S. \& Salomão, F.X.T. (1992) Evidências micromorfológicas do material de origem e da pedogênese quaternária dos solos podzólicos vermelho-amarelos no oeste do Estado de São Paulo. Belo Horizonte: Anais do Congresso da ABEQUA, 3, Anais: 65-87.

Santos, L.J.C. (1993) Análise micromorfológica da topossequiência Pousada da Esperança, Bauru-SP. Anais do XXIV Congr. Bras. De Ciências do Solo, Goiânia:-vol. II: 301-302.

Santos, L.J.C. (1995) Estudo morfológico da topossequiência da Pousada da Esperança, em Bauru, SP: subsídio para a compreensão da gênese, evolução e comportamento atual dos solos (Dissertação de Mestrado-Geografia/USP) 2v.

Santos, L.J.C. (2000) Pedogênese no Platô de Bauru (SP): o caso da bacia do Córrego da Ponte Preta (Tese de Doutorado-Geografia/USP), 183p.

Santos, L. J.C.; Castro, S.S. \& Salomão, F.X.T. (1996) Organizações Micromorfológicas e sua Relação com a Circulação Hídrica: O Exemplo de Bauru. Anais em Cdrom XIII Congr. Latino Americano de Ciências do Solo, Águas de Lindóia, SP, Brasil.

Santos, L.J.C.; Grimaldi, M.; Curmi, P.; Hallaire, V. \& Castro, S.S. (1998) Hydric behaviour of two soil covers (ferralsols and ferralsols/acrisols) on sandy stone (Brazil). Consequences in soil and relief organization. Res. Exp .Cdroom Montpellier. Anais: 16 th Int. Congr. of Soil Science, Montpellier, França.

Soares, P.C.; Landim, P.M..B.; Fülfaro, V.J. \& Sobreiro Neto, A.F. (1980) Ensaios de caracterização estratigráfica do cretáceo no Estado de São Paulo: Grupo Bauru. R. Bras. Geociências., São Paulo, 10 (3): 177-185.

Soil Survey Staff $(1960,1975)$ Soil Classification: a comprehensive system, 7th approximation. Washington D.C., U.S.D.A. Soil Cons. Service, $265 \mathrm{p}$.

Stoop, G. \& Jongerius, A. (1975) Proposal for micromorphological classification in soil material. I A classification of related distributions of coarse and fine particles. Geoderma, 13: 189-200.

Suguio, K. (2001) Geologia do Quaternário e Mudanças Ambientais.- passado + presente $=$ futuro? São Paulo:Paulos's Com. e Artes Gráficas (1999), 366p.

Suguio, K. \& Coimbra, A..M. (1976) Estudo sedimentológico das "bandas onduladas" de solos da Formação Bauru na área balizada pelas cidades de Oswaldo Cruz, Rancharia e Tupã, Estado de São Paulo. Bol. IG Inst. de Geoc./USP,7: 27-38. São Paulo.

Vidal-Torrado, P.; Lepsch, I.F.; Castro S.S. \& Cooper, M. (1999) Pedogênese em uma seqüência LatossoloPodzólico na borda de um platô na Depressão Periférica Paulista. R. Bras. Ciência do Solo, 23: 909-921.

Vidal-Torrado, P., Lepsch, I. F. \& Castro, S.S. (2005) Conceitos e Aplicações das Relações PedologiaGeomorfologia em Regiões Tropicais Úmidas. Tópicos em Ci. do Solo, 4, Viçosa, Soc. Bras. Ciência do Solo: 145-192. 